

\title{
Finite Element Modeling of Electroseismics and Seismoelectrics
}

Fabio Zyserman, Gauzellino Patricia Gauzellino, Laurence Jouniaux

\section{To cite this version:}

Fabio Zyserman, Gauzellino Patricia Gauzellino, Laurence Jouniaux. Finite Element Modeling of Electroseismics and Seismoelectrics. Niels Grobbe. Seismoelectric exploration: Theory, experiments and applications, , 2020, Book Series:Geophysical Monograph Series, 978-1-119-12737-6. 10.1002/9781119127383.ch18 . hal-03091019

\section{HAL Id: hal-03091019 https://hal.science/hal-03091019}

Submitted on 30 Dec 2020

HAL is a multi-disciplinary open access archive for the deposit and dissemination of scientific research documents, whether they are published or not. The documents may come from teaching and research institutions in France or abroad, or from public or private research centers.
L'archive ouverte pluridisciplinaire HAL, est destinée au dépôt et à la diffusion de documents scientifiques de niveau recherche, publiés ou non, émanant des établissements d'enseignement et de recherche français ou étrangers, des laboratoires publics ou privés. 


\title{
Finite element modelling of Electroseismics and Seismoelectrics
}

\author{
F. Zyserman ${ }^{1,2}$, P. Gauzellino ${ }^{2 *}$, L. Jouniaux ${ }^{3 \dagger}$ \\ ${ }^{1}$ Facultad de Ciencias Astronómicas y Geofísicas, Universidad Nacional de La Plata, Paseo del Bosque s/n, B1900FWA La \\ Plata, Argentina \\ ${ }^{2}$ CONICET \\ ${ }^{3}$ Institut de Physique du Globe de Strasbourg, EOST, UdS/CNRS UMR 7516, Université de Strasbourg, 5 rue René \\ Descartes, 67084, Strasbourg, France
}

*gauze@fcaglp.unlp.edu.ar

$\dagger_{1}$ jouniaux@unistra.fr

Corresponding author: F. Zyserman, zyserman@ fcaglp.unlp.edu .ar 


\section{Abstract}

In this chapter we describe a set of finite element formulations employed to approximate the solution to an extension to partially saturated porous media of Pride's equations, which is one of the most widespread theoretical frames that model the coupled electromagnetics and acoustics of saturated porous media. We also show how these numerical algorithms can be implemented on multi-core computers, and analyse their performance, observing that the parallel efficiency of the algorithms decays slower when the resources of each computing core are used as close to their maximum as possible. Further, we perform a study of two dimensional PSVTM electroseismic conversions in a time-lapse carbon dioxide geological deposition monitoring scenario, setting the electromagnetic source in depth, and measuring the seismic responses both in wells and at the surface. We observe that, contrary to what is known from standard field settings, the interface responses play no important role in elucidating the $\mathrm{CO}_{2}$ plume behaviour, and that the in-depth converted signals convey information about the carbon dioxide saturation in the plume.

\section{Introduction}

Geophysical methods of subsurface exploration are based on either seismic or electrical geophysical principles. The seismo-electromagnetic method combines both approaches, with the resolution of the seismics and the sensitivity of the electromagnetic methods to the fluids. It offers a non-invasive structure characterisation of the near surface earth from first few hundred meters up to the order of one thousand meters depth, in terms of fluids (water, oil, gas) [Dupuis et al., 2007; Haines et al., 2007a; Thompson et al., 2007]. It is usual to use different terms, according to the used source: Seismoelectrics (SE) involves generating a seismic wave and measuring the electrical field contained within or generated by it [Haartsen and Pride, 1997; Haines et al., 2007a,b], while electroseismics (ES) does the opposite by injecting a large amount of current into the ground and measuring the resulting seismic energy [Thompson et al., 2005, 2007]. First attempts on the seismic-electromagnetic effect were actually ES measurements, since an electric current was injected through the earth. The observations were thought to be due to changes in the earth resistivity under the influence of seismic waves. A first explanation was proposed to be linked to the fluctuations in the current through the electrolytic cell because of variations of the electro-chemical conditions at the surface of the electrodes, induced by the mechanical vibrations [Thyssen et al., 1937]. Then different experimental set-ups could eliminate the effect of electrode surface [Thompson, 1939]; and later on Pride [1994]; 
Butler et al. [1996] showed that the resistivity modulation was not the relevant mechanism of the observed SE signals. Decades ago, Thompson and Gist [1993] observed conversions from electromagnetic to seismic energy at the siliciclastics Friendswood test site (Texas), with the presence of a sequence of high permeability water sands and low permeability shales over 300 m depth. They showed through modelling that electroseismics are more sensitive to low permeability formations whereas seismoelectrics are most sensitive to high permeability formations. Over the last two decades some observations showed that the electroseismic conversions could yield conversions of higher energy efficiency. First successful demonstration that electroseismic conversions can distinguish between aquifers and gas sands and can be used at depths up to $1000 \mathrm{~m}$ using geophones placed on the surface of the earth were provided by [Thompson et al., 2007; Hornbostel and Thompson, 2007].

The pioneering studies of Reuss [1809], Wiedemann [1852], von Helmholtz [1879], Smoluchowski [1903] and Frenkel [1944] were completed in more recent times with the development of the corresponding theory. Thompson and Gist [1993] and Pride [1994] explained the electrokinetic coupling mechanism within the double electrical layer at the solid-fluid interface. Electro-osmotic flow occurs when an electric field acts on the electrolytes present in the fluids. This generates pressure gradients and, therefore, fluid flow and mechanical macroscopic perturbations, yielding the SE technique. Equally important is the reciprocal case called electrofiltration. In this one, an applied pressure gradient creates fluid flow and consequently, an ionic convection current, which in turn produces an electric field, phenomenon upon which ES is based. Pride [1994] derived the equations for both phenomena (ES-SE) whose linking factor is the so-called electrokinetic coupling coefficient. The uncoupled Biots equations for fluidsaturated porous media [Biot, 1956a,b] and Maxwell's equations take place if this coefficient is zero; for a review on this or other theoretical frames for the electroosmotic and electrofiltration phenomena, and hence for SE and ES see Jouniaux and Ishido [2012]; Jouniaux and Zyserman [2016].

The computation of approximate solutions to any of the several model equations governing the rise of electromagnetic signals due seismic waves traversing a fluid saturated porous medium or conversely, the rise of seismic waves due to electromagnetic probes, is not a simple task. We review now a small part of the literature on this topic, focusing ourselves mainly on the numerical treatment of Pride's equations, which are the ones we deal with in this chapter. Haartsen and Pride [1997] performed numerical modelling featuring seismic and electromagnetic point sources on horizontally stratified media; they used a global matrix method to 
obtain their results. They showed that Pride's equations can be decoupled in two modes, namely the SHTE (horizontal shear wave transverse electric field) mode, involving the seismic SH and transverse electric TE, and the PSVTM (transverse magnetic field of vertical P and S waves) mode, linking the seismic P-SV modes with the transverse magnetic TM mode; further they showed that the interface response was similar to the one of a vertical electric dipole situated right beneath the seismic source. Mikhailov et al. [1997] used this algorithm to analyse field measurements involving IR responses at a top soil-glacial till interface and later $H u$ and Gao [2011] extended this algorithm by including a moment tensor point source. Han and Wang [2001] proposed a finite element procedure in time-domain for modelling diffusive electric fields induced by pure shear waves. Garambois et al. [2002] presented a numerical simulation for SE events through the generalized reflection and transmission matrix method, extended afterwards by Warden et al. [2013] to unsaturated conditions to perform a study of the vadose zone. The works developed by Pain et al. [2005] and Haines and Pride [2006] describe a mixed finite element algorithm for ES in boreholes and a finite-difference procedure that applies ES in heterogeneous media, respectively. Also, Guan and Hu [2008] introduced a finite-difference timedomain method with perfectly matched layer (PML) technique as boundary conditions in borehole geometries (cylindrical symmetry). They calculated ES and SE logging responses to estimate the parameters of the porous medium around the borehole. A variation of this numerical technique was employed recently by Zheng et al. [2015] when simulating the electric field excited by the acoustic wave in a logging while drilling scenario. Two dimensional numerical tests about P-TM conversions using an implicit time stepping finite element algorithm in a commercial software were implemented by Kröger et al. [2014], while Zhou et al. [2014] studied converted waves inside a borehole setting boundary conditions at the interface between fluid and porous media. Receivers along the vertical axis of the borehole detected the components of electric and magnetic field depending on the distance from the acoustic source. In a series of works Grobbe and Slob [2013, 2014]; Grobbe et al. [2014]; Grobbe and Slob [2016] presented and applied the algorithm ESSEMOD, which is a layered-Earth analytically based simulation code, implementing all existing possible seismo-electromagnetic and electro-magnetoseismic sourcereceiver combinations. This code can presently model fluid/porous medium/fluid transitions, thereby enabling studying typical seismo-electromagnetic laboratory wave propagation experiments, as the authors did in the third of these last references. In the last one, they studies the responses of different thin-bed packages, proving that the seismo- electromag- 
netic responses are sensitive to changes in medium parameters in length scales much smaller than the seismic resolution.

Recently, using one dimensional versions of the numerical algorithms presented in this work, Zyserman et al. [2015] could demonstrate that the seismoelectric and seismomagnetic interface responses generated at boundaries of a layer containing carbon dioxide are sensitive to its $\mathrm{CO}_{2}$ content; and Munch and Zyserman [2016] analysed how the seismoelectric interface responses vary when a superficial aquifer is contaminated with light or dense NAPLs.

In this chapter, the differential model consists in Maxwell and Biot equations; the numerical formulation uses a mixed finite element technique to approximate the electromagnetic wave fields and a non-conforming finite element procedure to approximate the solid displacements with the vector part of the Raviart-Thomas-Nedelec space of zero order to the fluid displacements for the seismic wave fields, see e.g. [Raviart and Thomas, 1975; Nedelec, 1980; Douglas, Jr. et al., 1999; Zyserman and Santos, 2000; Santos and Sheen, 2007; Santos, 2009; Zyserman et al., 2010; Savioli et al., 2014] for other works where these spaces are used and analysed. The iterative non-overlapping domain decomposition algorithm proposed here [Santos and Sheen, 2007; Savioli et al., 2014] allows to solve problems with a large number of unknown and it is suitable to be implemented on computers with parallel architecture [Zyserman and Santos, 2000; Gauzellino et al., 2009; Zyserman et al., 2012]. We consider that events of feedback are neglected, and therefore Maxwell and Biot equations can be solved separately. Here, the fluid-saturated porous medium is characterizated by effective models and viscoelastic behaviour [Carcione, 2001] also taken into account. With respect to the electromagnetic part, the electrical conductivity and electrokinetic coefficient are expressed as a function of the water saturation.

Our algorithm is applied to a case of time-lapse $\mathrm{CO}_{2}$ geological sequestration scenario, where we analyse the seismic response to different saturations of $\mathrm{CO}_{2}$. Finally, we would like to mention that although not included in this chapter, examples of applications of the presented algorithm to seismoelectric case studies can be found in [Gauzellino et al., 2010a,b].

\section{Simplifying and extending Pride's equations}

With the goal of making the SE/ES equations more tractable, it is usual to introduce simplifying assumptions by reducing the dimensionality of the equations and/or by decoupling the full set of Pride's equations in one of two different ways: if the electroosmotic feedback is neglected, the poroelastic equations can be decoupled from the electromagnetic ones; this is usu- 
ally done in SE. If the electrofiltration feedback can be neglected, Maxwell's equations can be decoupled from Biot's equations; this is the chosen way when dealing with ES problems. In both cases the uncoupling can be safely carried out if the condition

$$
\frac{\eta \mathcal{L}^{2}(\omega)}{k(\omega) \sigma^{e}} \ll 1
$$

is fulfilled [Haines and Pride, 2006; Hu et al., 2007; Guan and Hu, 2008; Zyserman et al., 2010]; here $\eta$ stands for the fluid viscosity, $\mathcal{L}(\omega)$ for the electrokinetic coupling coefficient, $k(\omega)$ for the dynamic permeability and $\sigma^{e}$ for the electric conductivity. Most of the works present in the literature take this condition as granted, and likewise we proceed in the present chapter. In this way, to model a SE problem, Biot's equations are solved in a first instance to obtain solid and fluid displacements generated by a seismic source, and in a second step, the electromagnetic responses are got; the fluid displacements are a constitutive part of the electromagnetic source. On the other hand, in an ES problem, Maxwell's equations are solved to get the electric and magnetic fields created by electric currents, and the former is used in the source term of the poroelastic equations to obtain, in a second step, the induced seismic wave fields.

\subsection{Problem dimensionality}

Considering the dimensionality of the problem, until now there has been, to the authors' knowledge, just one attempt to solve Pride's equations involving finite sources and three dimensional geometries and fields [Wang et al., 2013a], and it has been done using the finite differences technique. The difficulty in numerically modelling fully three dimensional problems is the huge amount of unknowns involved, which implies the usage of very large computing resources. Because of this reason, we restrict ourselves to show finite element algorithms for two dimensional problems; that is, we consider in the next sections either seismic or electromagnetic sources generating two dimensional vector fields, which interact with two dimensional Earth models and induce two dimensional responses.

\subsection{Extended models}

The extension of the original set of SE/ES equations to deal with partially saturated or contaminated soils is usually carried out by having recourse to effective media models, as can be seen in the works of Zyserman et al. [2010]; Warden et al. [2013]; Bordes et al. [2015]; Zyserman et al. [2015]; Munch and Zyserman [2016]. There exist also other approaches considering Biot-type formulations, such as the composite media approach proposed by Zyserman 
et al. [2012] to deal with the presence of methane hydrates, or the recent contribution by Jardani and Revil [2015], where the theory is enlarged to deal with mixtures of immiscible fluids. We use the effective media approach in the case study we present in this chapter -involving a $\mathrm{CO}_{2}$ geological deposition situation-, so we show now how the model parameters are dealt with. The rock physics models we show below are widely employed in the literature, but the reader should recall that they are approximations and their validity must be tested, as we did in this work. Moreover, other approximations do exist for most of the effective parameters [Mavko et al., 2009].

For the effective fluid mass density, calculated in terms of the water density $\rho^{w}, \mathrm{CO}_{2}$ density $\rho^{C O_{2}}$ and their respective saturations $S_{w}$ and $S_{\mathrm{CO}_{2}}$ we use

$$
\rho^{E}=\rho^{w} S_{w}+\rho^{C O_{2}}\left(1-S_{w}\right),
$$

where $S_{w}+S_{\mathrm{CO}_{2}}=1$ is assumed. For the effective bulk modulus of such fluid mixture we use Brie et al. [1995]

$$
K^{f}=\left(K^{w}-K^{C O_{2}}\right) S_{w}^{5}+K^{C O_{2}}
$$

the power five in this expression is chosen following Carcione et al. [2006a]. Here the $\mathrm{CO}_{2}$ is supercritical, so there is no gaseous phase in our model. The effective viscosity is computed in terms of the mixture components viscosities $\eta^{l}, l=w, C O_{2}$ and water saturation $S_{w}$ using Teja and Rice [1981]

$$
\eta=\eta^{C O_{2}}\left(\frac{\eta^{w}}{\eta^{C O_{2}}}\right)^{S_{w}}
$$

In order to compute the saturated rock matrix properties, we proceed as follows: we consider three different materials building the solid matrix, namely sand, silt and clay, and we call $\gamma_{\text {sand }}$, $\gamma_{\text {silt }}$ and $\gamma_{\text {clay }}$ their respective volume fractions; $\gamma_{\text {sand }}+\gamma_{\text {silt }}+\gamma_{\text {clay }}=1$. The mass density of the aggregate $\rho^{s}$ is given by the volume weighted mean of the respective components mass densities,

$$
\rho^{s}=\gamma_{\text {sand }} \rho^{s, \text { sand }}+\gamma_{\text {silt }} \rho^{s, \text { silt }}+\gamma_{\text {clay }} \rho^{s, \text { clay }},
$$

and the bulk mass density is calculated as usual,

$$
\rho^{b}=\rho^{s} \phi+\rho^{f}(1-\phi),
$$

where $\phi$ is the rock porosity. The bulk modulus $K^{s}$ and shear modulus $G^{s}$ of the mixture of mineral grains are given by the Reuss average of the components bulk and shear moduli respectively [Mavko et al., 2009]

$$
K^{s}=\left(\frac{\gamma_{\text {sand }}}{K^{s, \text { sand }}}+\frac{\gamma_{\text {silt }}}{K^{s, \text { silt }}}+\frac{\gamma_{\text {clay }}}{K^{s, \text { clay }}}\right)^{-1}
$$


and

$$
G^{s}=\left(\frac{\gamma_{\text {sand }}}{G^{s, \text { sand }}}+\frac{\gamma_{\text {silt }}}{G^{s, \text { silt }}}+\frac{\gamma_{\text {clay }}}{G^{s, \text { clay }}}\right)^{-1} .
$$

The solid matrix bulk modulus $K^{f r}$ and shear modulus $G^{f r}$ are then calculated by Krief's model as

$$
K^{f r}=K^{s}(1-\phi)^{(3 /(1-\phi))}, \quad G^{f r}=G^{s}(1-\phi)^{(3 /(1-\phi))} .
$$

The expressions in this equation have been used to deal with shaley sand data [Mavko et al., 2009].

The shear modulus of the effective fluid saturated rock matrix $G_{u}$ is considered, as usual, equal to $G^{f r}$, but for the saturated matrix bulk modulus $K_{u}$ we use Gassman's approach as follows [Gassmann, 1951; Santos et al., 1992]

$$
K_{u}=K^{f r}+\alpha^{2} K^{a v}, \quad K^{a v}=\left[\frac{\alpha-\phi}{K^{s}}+\frac{\phi}{K^{f}}\right]^{-1}, \quad \alpha_{B}=1-\frac{K^{f r}}{K^{s}} .
$$

In this equation, $K^{a v}$ and $\alpha_{B}$ are the so called fluid-storage and Biot-Willis coefficients respectively. The reader should recall here that Gassmann's model is valid for seismic frequencies, but for sonic or ultrasonic ones, other models taking into account squirt flow [Mavko and Jizba, 1991; Dvorkin and Nur, 1993; Dvorkin et al., 1995] should be employed.

The model can be further extended if the diverse energy loss mechanisms present in the subsurface, which are not explicitly considered in Biot's equations are taken into account. One example of these mechanisms is the so called wave induce fluid flow, studied by several authors [Pride et al., 2004; Rubino et al., 2008; Picotti et al., 2007; Song et al., 2016]. With this goal, instead of considering particular loss processes, we consider that the studied region presents a viscoelastic behaviour, and we use Biot's correspondence principle [Biot, 1956c, 1962], replacing the (real) relaxed elastic moduli $G$ and $K$ by complex frequency dependent viscoelastic moduli. To obtain their expressions we employ Liu's linear viscoelastic model [Liu et al., 1976], which reads for $G$ (we deal with $K$ in the same fashion): $\widehat{G}(\omega)=G /(R(\omega)-i T(\omega))=$ $G_{r}(\omega)+i G_{i}(\omega)$. The functions $R(\omega)$ and $T(\omega)$, associated with a continuous spectrum of relaxation times, characterize the viscoelastic behaviour and are given by

$$
R(\omega)=1-\frac{1}{\pi \widehat{Q}} \ln \frac{1+\omega^{2} T_{1}^{2}}{1+\omega^{2} T_{2}^{2}}, \quad T(\omega)=\frac{2}{\pi \widehat{Q}} \tan ^{-1} \frac{\omega\left(T_{1}-T_{2}\right)}{1+\omega^{2} T_{1} T_{2}} .
$$

The model parameters $\widehat{Q}, T_{1}$ and $T_{2}$ are taken such that the quality factor $Q(\omega)=\frac{G_{r}(\omega)}{G_{i}(\omega)}$ is approximately equal to the constant $\widehat{Q}$ within the frequency range we deal with in this work. Values of $\widehat{Q}$ range from $\widehat{Q}=10$ for highly lossy materials to about $\widehat{Q}=1000$ for almost elastic ones. We used $\widehat{Q}=100, T_{1}=\frac{1}{2 \pi} 10^{6} s$ and $T_{2}=\frac{1}{2 \pi} 10^{-7} s$ in all the examples shown 
below. Although there are other models to account for the energy loss, e.g. [Chotiros and Isakson, 2004], we used Liu's model because it provides a constant quality factor over the frequency range considered, the moduli are well behaved at $\omega \rightarrow 0$ and ensures causality, which is a reasonable behaviour for geophysical applications.

For the absolute permeability $k_{0}$ of the porous medium we use [Mavko et al., 2009]

$$
k_{0}=B \frac{\phi^{3}}{(1-\phi)^{2}} d_{k}^{2} \quad \text { where } \quad \frac{1}{d_{k}}=\frac{\gamma_{\text {sand }}}{r_{\text {sand }}}+\frac{\gamma_{\text {silt }}}{r_{\text {silt }}}+\frac{\gamma_{\text {clay }}}{r_{\text {clay }}} .
$$

Here $B$ is a geometric constant (we assume $B=0.003$ [Carcione and Picotti, 2006]) and $r_{*}$ is the radius of the different rock constituent particles.

In order to characterize the electric conductivity of the effective fluid saturated solid matrix we use the expression recently proposed by Warden et al. [2013], extending Pride's original formula [Pride, 1994, Eq.(242)] to the realm of partially saturated media:

$$
\sigma_{e f f}^{*}\left(S_{w}, \omega\right)=\frac{S_{w}^{n}}{F} \sigma^{w}+\frac{2}{F} \frac{C_{e m}+C_{o s}^{*}(\omega)}{\Lambda}
$$

The first term in this equation -where $F=\phi^{-m^{c}}$ stands for the formation factor, $m^{c}$ being the cementation coefficient- is Archie's law for a partially saturated medium, while the second term accounts for the surface conductivity. The water electrical conductivity $\sigma^{w}=\sum_{l=N a^{+}, C l^{-}}\left(e z_{l}\right)^{2} b_{l} N_{l}$, where $e=1.6 \times 10^{-19} \mathrm{C}$ is the electron electric charge, and $z_{l}$ is the ions' valence, taken to be one for both species. The ions' mobility $b_{l}$ and concentration $N_{l}$ (depending on the salinity $C_{0}$ )) are calculated following Carcione et al. [2003]. In the second term, accounting for the surface conductivity, the factor $C_{e m}[\mathrm{~S}]$ is the excess conductance associated with the electromigration of double layer ions; $C_{o s}^{*}(\omega)[\mathrm{S}]$ is the frequencydependent electro-osmotic conductance due to electrically induced streaming of the excess doublelayer ions and $\Lambda[\mathrm{m}]$ is the above presented pore-geometry dependent factor. We remark here that, as in Brovelli et al. [2005] and Warden et al. [2013], the surface conductivity is assumed to be independent of water saturation $S_{w}$, because under realistic saturation ranges (residual water saturation $S_{w r} \geq 10 \%$ ) the thickness of the wetting phase layer on the pore surface is always larger than the Debye length $d^{l}$. This also means that all fluid related properties involved in the calculation of the surface conductivity and of the electrokinetic coupling -see below- are just those of water.

Again, following Warden et al. [2013], we propose for the effective fluid saturated media the following electrokinetic coupling:

$$
\mathcal{L}_{0}\left(S_{w}\right)=-\frac{\phi}{\alpha_{\infty}} \frac{\varepsilon^{w} \zeta^{p}}{\eta^{w}}\left(1-2 \frac{d^{l}}{\Lambda}\right) S_{w}^{n} \mathcal{C}\left(S_{w}\right)
$$


In this equation $\alpha_{\infty}=\phi F$ is the tortuosity, $\varepsilon^{w}$ is the water electric permittivity, $n$ is Archie's saturation exponent (taken to be equal to the cementation exponent $m^{c}$ ), $d^{l}$ is the Debye length and $\mathcal{C}\left(S_{w}\right)$ is a function relating the streaming potential coefficient obtained under partial saturation conditions to the one corresponding to full saturation conditions. Several authors have investigated this relation from both theoretical and experimental viewpoints. In the study of Strahser et al. [2011], different models for the streaming potential coefficient (SPC) dependence on $S_{w}$ were considered, namely the ones by Perrier and Morat [2000], Revil et al. [2007], Guichet et al. [2003] and Allègre et al. [2010]. Characterizing this dependence by a power law has been also proposed to model the relative electrokinetic coefficient in an imbibition experiment [Saunders et al., 2008]. Jackson [2010] also used a capillary tubes model making explicit the SPC dependence with water saturation, relative permeability and relative charge density. Further models derived from considerations on how the excess charge dragged by the water varies with water saturation may be mentioned, as those derived by Mboh et al. [2012] and Jougnot et al. [2015]. Recently, Allègre et al. [2012] modelled both Richards' equation for hydrodynamics and Poisson's equation for electrical potential for unsaturated conditions, using a 1-D finite element method. They concluded, based on laboratory experiments [Allègre et al., 2010, 2011] and using these equations, that the unsaturated electrokinetic coefficient should have a non-monotonous behaviour. Moreover experimental results from periodic succession of drainage and imbibition cycles on sand suggested that the airwater interface that develops for unsaturated conditions polarizes and therefore generates an electrical response [Allègre et al., 2014]. Finally Allègre et al. [2015] showed that the interface between water and air should also be taken into account, since this interface is negatively charged, as the interface between the rock matrix and the water. Moreover during a drainage the amount of this interface does not decrease with decreasing water saturation, but first increases before decreasing, leading to a nonmonotonic behaviour of the resulting SPC [Allègre et al., 2015].

For the present we select the following relation, displaying a non monotonic dependence with water saturation [Allègre et al., 2010]:

$$
\mathcal{C}\left(S_{w}\right)=\left(\frac{S_{w}-S_{w r}}{1-S_{w r}}\right)\left[1+32\left[1-\left(\frac{S_{w}-S_{w r}}{1-S_{w r}}\right)\right]^{0.4}\right], \quad S_{w r}=0.20,
$$

in Fig. 1 the behaviour of $\mathcal{C}\left(S_{w}\right)$, where its sharp decrease for $S_{w} \geq 0.8$ is remarkable.

Finally, notice that in order to write Eq. (13), it was assumed in Warden et al. [2013] that the surface electrical conductivity is negligible against the electrical bulk conductivity; a requirement fulfilled in this work due to chosen values for the salinity $C_{0}$. On the other hand, we compute the zeta potential $\zeta^{p}$ as $\zeta^{p}=0.008+0.026 \log _{10}\left(C_{0}\right)$ [Pride and Morgan, 1991]. 


\section{Domain decomposition and Finite elements formulation}

In this section the treatment of the ES PSVTM-mode is described; the ES SHTE-mode and both modes of the SE case treated in similar way. We assume that the chosen soil properties and seismic frequency range guarantee that any considered angular frequency $\omega$ renders displacements currents that are negligible against conduction currents, i.e. $\epsilon \omega \ll \sigma$, and that it is well below Biot's critical frequency. Because of this reason, we use the static values $k_{0}$ and $\mathcal{L}_{0}$ instead of the dynamic ones $k(\omega)$ and $\mathcal{L}(\omega)$ for the permeability and electrokinetic coupling coefficient respectively.

We present below different kinds of mixed finite elements, which we use to approximate the solutions to both Maxwell's equations and Biot's equations; noting that previously to this step we apply to them domain decomposition (DD) procedures. The DD technique can be used at different levels [Toselli and Widlund, 2005]: continuous, discrete, or in the solution of the linear systems arising from the approximation of different partial differential equations. The domain decomposition procedures (DD) here presented belong to the continuous level, and are iterative methods that converge to the solution of the respective global procedures [Santos, 1998, 2009]; for different implementations, mainly involving the first and third mentioned levels, the reader can see, for example, references Japhet and Nataf [2001]; Gander et al. [2002, 2004].

The idea is to solve in parallel a collection of elliptic problems in the space-frequency domain with absorbing boundary conditions at artificial boundaries. Then, the solution in the time domain is obtained using the inverse Fourier transform.

Among the advantages of the presented procedure to solve wave propagation phenomena we can indicate:

- DD combined with any finite element method bypasses storage and solution of the large linear systems.

- In structured finite element meshes, DD is specifically designed to profit of the parallel architecture.

- Nonconforming finite element space significantly reduces the amount of information exchanged among processors.

- The rate of convergence of the iterative algorithm can be estimate using nonconforming finite element spaces. 


\subsection{Maxwell's equations}

Let us then start by considering a domain $\Omega=\Omega^{a} \cup \Omega^{s}$ comprising air and subsurface, with boundary $\Gamma$. The domain $\Omega$ is partitioned into non overlapping subdomains $\Omega_{j}$ with boundary $\Gamma_{j}$ as shown in Fig.2(a). Let also $\Omega_{j}$ and $\Omega_{\mathrm{k}}$ be two adjacent subdomains of the domain decomposition, and $\Gamma_{j \mathrm{k}}$ their common boundary. Assuming that we are dealing with the TM mode, where the present electromagnetic fields are $E \equiv\left(E_{x}(x, z, \omega), E_{z}(x, z, \omega)\right)$ and $H \equiv H_{y}(x, z, \omega)$, the domain decomposed formulation of Maxwell's equations reads [Zyserman et al., 1999; Zyserman and Santos, 2000]:

$$
\begin{aligned}
& \sigma^{e} E_{\mathrm{j}}-\left(-\partial_{z} H_{\mathrm{j}}, \partial_{x} H_{\mathrm{j}}\right)=J^{m} \quad \text { in } \Omega_{\mathrm{j}}, \\
& \partial_{z} E_{x, \mathrm{j}}-\partial_{x} E_{z, \mathrm{j}}+i \omega \mu H_{\mathrm{j}}=0 \quad \text { in } \Omega_{\mathrm{j}}, \\
& H_{\mathrm{j}}+\beta_{\mathrm{jk}} E_{\mathrm{j}} \cdot \chi_{\mathrm{j}}=-\beta_{\mathrm{jk}} E_{\mathrm{k}} \cdot \chi_{\mathrm{k}}+H_{\mathrm{k}} \quad \text { on } \Gamma_{\mathrm{jk}} \\
& H_{\mathrm{k}}+\beta_{\mathrm{jk}} E_{\mathrm{k}} \cdot \chi_{\mathrm{k}}=-\beta_{\mathrm{jk}} E_{\mathrm{j}} \cdot \chi_{\mathrm{j}}+H_{\mathrm{j}} \text { on } \Gamma_{\mathrm{kj}} \\
& (1-i) \sqrt{\frac{\sigma^{e}}{2 \omega \mu}} E_{\mathrm{j}} \cdot \chi_{\mathrm{j}}+H_{\mathrm{j}}=0 \quad \text { on } \quad \Gamma .
\end{aligned}
$$

The first two of this set of equations are Ampere-Maxwell's and Faraday's respectively; in them we denote the partial derivative with respect to coordinate $x$ as $\partial_{x} ; J^{m}$ is the external source creating the TM polarized fields and $\mu$ is the magnetic permeability. Eqs. (17)-(18) are Robin boundary conditions [Douglas et al., 1993; Kim, 1995] imposed on the boundaries between any two domains to ensure consistency of the global solution; $\chi$ is a vector tangent to the considered boundary and $\beta$ a complex parameter; it is used to improve the efficiency of the iterative algorithm defined below. Finally, Eq. (19) is an absorbing boundary condition (ABC) approximating the Silver-Müller radiation condition for infinite domains imposed on the boundary $\Gamma$ of the computational domain $\Omega$ [Sheen, 1997]. In order to approximate the solution to these equations an iterative hybridized mixed domain decomposed finite element procedure is implemented [Zyserman et al., 2010, 2012]. As already mentioned, the main concept underlying this method is to split the problem in a collection of small ones whose individual solutions can be easily computed.

Consider then, as approximating mixed finite element spaces the following ones

$$
\begin{gathered}
V^{h}=\left\{E^{h} \in L^{2}(\Omega):\left.E^{h}\right|_{\Omega_{\mathrm{j}}} \in P_{0,1} \times P_{1,0}\right\}, \\
W^{h}=\left\{H^{h} \in L^{2}(\Omega):\left.H^{h}\right|_{\Omega_{j}} \in P_{0,0}\right\}, \\
V_{j}^{h}=\left.V^{h}\right|_{\Omega_{\mathrm{j}}}, \quad W_{\mathrm{j}}^{h}=\left.W^{h}\right|_{\Omega_{\mathrm{j}}} .
\end{gathered}
$$


Here $P_{1,0}$ denotes a polynomial of degree less or equal 1 in $x$ and less or equal 0 in $z$. Then, in each element, we approximate the magnetic field with a two dimensional vector, whose components are first order polynomials and the electric field with a constant. Therefore, these spaces have five degrees of freedom associated with each element, four to the electric field and one to the magnetic field, respectively. These degrees of freedom for TM mode are at the centres of the faces and centre of each element as shown in Fig.2(b).

Let us assume that the finite element partition exactly coincides with the domain decomposition, and denote with $(\cdot, \cdot)$ and with $\langle\cdot, \cdot\rangle$ the inner product in an element and on the boundary of an element respectively. Using these conventions, the iterative algorithm implemented for each frequency $\omega$ reads:

Find $\left(E_{\mathrm{j}}^{h, n+1}, H_{\mathrm{j}}^{h, n+1}, \ell_{\mathrm{jk}}^{h, n+1}\right) \in V_{\mathrm{j}}^{h} \times W_{\mathrm{j}}^{h} \times \Psi_{\mathrm{jk}}^{h}$ such that

$$
\begin{aligned}
& \left(\sigma^{e} E_{\mathrm{j}}^{h, n+1}, \partial_{z} \psi-\partial_{x} \psi\right)_{\Omega_{\mathrm{j}}}-\left(H_{\mathrm{j}}^{h, n+1}, \psi\right)_{\Omega_{\mathrm{j}}}+\sum_{\substack{\mathrm{k} \\
\Gamma_{\mathrm{jk}} \cap \Gamma=\phi}}\left\langle\beta_{\mathrm{jk}} E_{\mathrm{j}}^{h, n+1} \cdot \chi_{\mathrm{j}}, \psi \cdot \chi\right\rangle_{\Gamma_{j \mathrm{k}}} \\
& +\left\langle(1-i) \sqrt{\frac{\sigma^{e}}{2 \omega \mu}} E_{\mathrm{j}}^{h, n+1} \cdot \chi_{\mathrm{j}}, \psi \cdot \chi_{\mathrm{j}}\right\rangle_{\Gamma \cap \Gamma_{\mathrm{j}}}= \\
& -\left(J^{m}, \psi\right)_{\Omega_{\mathrm{j}}}-\sum_{\substack{\mathrm{k} \\
\Gamma_{\mathrm{jk}} \cap \Gamma=\phi}}\left\langle\beta_{\mathrm{jk}} E_{\mathrm{k}}^{h, *} \cdot \chi_{\mathrm{k}}-H_{\mathrm{k}}^{h, *}, \psi \cdot \chi\right\rangle_{\Gamma_{\mathrm{jk}}}, \quad \psi \in V_{\mathrm{j}}^{h}, \\
& \left(\left(\partial_{z} E_{\mathrm{j}}^{h, n+1}-\partial_{x} E_{\mathrm{j}}^{h, n+1}\right), \varphi\right)_{\Omega_{\mathrm{j}}}+\left(i \omega \mu H_{\mathrm{j}}^{h, n+1}, \varphi\right)_{\Omega_{\mathrm{j}}}=0, \quad \varphi \in W_{\mathrm{j}}^{h}, \\
& \lambda_{\mathrm{jk}}^{h, n+1}=\lambda_{\mathrm{kj}}^{h, *}-\beta_{\mathrm{jk}}\left(E_{\mathrm{j}}^{h, n+1} \cdot \chi_{\mathrm{j}}+E_{\mathrm{k}}^{h, *} \cdot \chi_{\mathrm{k}}\right) \quad \text { on } \Gamma_{\mathrm{jk}}, \quad \Gamma_{\mathrm{jk}} \cap \Gamma=\phi .
\end{aligned}
$$

The mentioned complex parameter $\beta$ is chosen as $\beta_{j k}=\frac{1}{2}\left(\sqrt{\frac{\sigma_{j}^{e}}{2 \omega \mu}}+\sqrt{\frac{\sigma_{k}^{e}}{2 \omega \mu}}\right)$. The system of equations (23)-(25) yields an algebraic system of nine equations in each element/subdomain. The Lagrange multipliers appearing in (25) are approximations to the magnetic field on the boundaries of the elements; they are introduced following a technique called hybridization, see Santos [2009] and references therein. As the magnetic field is assumed to be piecewise constant, they are necessary to avoid -because of the continuity condition of the tangential component of the magnetic field- the constant solution throughout the computational domain. With this in mind, the space

$$
\Psi^{h}=\left\{\ell^{h}:\left.\ell^{h}\right|_{\Gamma_{\mathrm{jk}}}=\ell_{\mathrm{jk}}^{h} \in\left[P_{0}\left(\Gamma_{\mathrm{jk}}\right)\right]^{2} \equiv \Psi_{\mathrm{jk}}^{h}, \ell_{\mathrm{jk}}^{h}+\ell_{\mathrm{kj}}^{h}=0\right\}
$$

is introduced, where $P_{0}\left(\Gamma_{\mathrm{jk}}\right)$ denotes the constant functions defined on $\Gamma_{\mathrm{jk}}$.

From one of the five equations originated in Eqs. (23)-(24) the magnetic field can be calculated; from the other four equations the electric field unknowns can be obtained, each one of the them computed just in terms of the calculated magnetic field unknown. 
Further, notice that to the right hand side of each element contribute both the external source -evaluated in the centroid of the element- and the (already known) unknowns coming from adjacent elements (see last term of equation (23)).

\subsubsection{Iterative schemes}

The $*$ appearing as superscript of the fields and Lagrange multipliers in the right hand side of the iterative procedure given by (23)-(25) has different meanings, depending on how the iterative procedure is effectively implemented. For a Jacobi-type iterative algorithm, $*=$ $n$, a Seidel-type algorithm is obtained if for all subdomains $\Omega_{\mathrm{k}}$ such that $\mathrm{j}<\mathrm{k}, *=n+1$ and for the ones such that $\mathrm{j}>\mathrm{k}, *=n$. Other possible choice is the so called "Red-Black" scheme; in it half of the subdomains of the partition are labelled "Red", the other half "Black", and are disposed such that a Red subdomain has Black ones as first neighbours. In this scheme, $*=n+1$ if $\Omega_{\mathrm{j}}$ is a Red subdomain, and $*=n$ if it is a Black one. In Figure 5 we display two different implementations of this scheme; in Fig. 5a the domain decomposition coincides with the finite element partition, so that the Red-Black scheme, depicted using black and white squares, has the pattern of a chess-board, we call this option "Massive domain decomposition (MDD)". On the other hand, Fig. 5b displays a situation in which each domain involves several elements of the finite element partition; this is the "Stripes domain decomposition (SDD)". The number of iterations necessary to reach convergence is dependent of the chosen implementation [Gauzellino et al., 2009].

In summary, if the MDD implementation of the Red-Black scheme is chosen, for each frequency $\omega$ the algorithm reduces to calculate in each iteration, nine algebraic equations (five for the fields and four for the Lagrange multipliers) in each one of the $n_{x} \cdot n_{z}$ elements. On the other hand, the number of degrees of freedom of the SDD implementation of the Red-Black scheme depends on how the discrete problem is solved within each stripe. Several options have been investigated in Gauzellino et al. [2009] when solving a three dimensional Helmholtz equation; it was there concluded that the MDD implementation of the Red-Black scheme is the most efficient.

\subsection{Biot's equations with electroosmotic source}

Once the electric field $E_{\mathrm{j}}$ is known in all domains $\Omega_{\mathrm{j}} \in \Omega$, i.e., when the iterative procedure defined in the previous section has converged, we are in a position to calculate the induced fluid filtration in the partially saturated poroelastic medium $\Omega^{s}$. We start by adding some 
notation; let $\nu_{\mathrm{jk}}$ be the outer normal on $\Gamma_{\mathrm{jk}}$ from $\Omega_{\mathrm{j}}$ to $\Omega_{\mathrm{k}}$ and $\nu_{\mathrm{j}}$ the outer normal to $\Gamma_{\mathrm{j}}$, see Fig.3(a). We continue by writing the domain decomposed Biot's equations, in which we want to find for every subdomain $\Omega_{\mathrm{j}} \in \Omega^{s}$ the displacements $u_{\mathrm{j}}=\left(u_{\mathrm{j}}^{s}, u_{\mathrm{j}}^{f}\right)$, where $u_{\mathrm{j}}^{s} \equiv\left(u_{x}^{s}(x, z, \omega), u_{z}^{s}(x, z, \omega)\right)_{\Omega_{\mathrm{j}}}$ is the solid displacement and by $u_{j}^{f} \equiv\left(u_{x}^{f}(x, z, \omega), u_{z}^{f}(x, z, \omega)\right)_{\Omega_{\mathrm{j}}}$ the relative fluid displacement per unit volume of bulk material in the subdomain $\Omega_{\mathrm{j}}$ solutions to

$$
\begin{aligned}
& -\omega^{2} \rho^{b} u_{\mathrm{j}}^{s}-\omega^{2} \rho^{E} u_{\mathrm{j}}^{f}-\nabla \cdot \tau^{b}\left(u_{\mathrm{j}}\right)=0, \\
& -\omega^{2} \rho^{E} u_{\mathrm{j}}^{s}-\omega^{2} g_{0} u_{\mathrm{j}}^{f}+i \omega \frac{\eta}{k_{0}} u_{\mathrm{j}}^{f}+\nabla p_{f}=\frac{\eta}{k_{0}} \mathcal{L}_{0} E_{\mathrm{j}}, \\
& \tau_{l m}\left(u_{\mathrm{j}}\right)=2 G^{f r} \varepsilon_{l m}\left(u_{\mathrm{j}}^{s}\right)+\delta_{l m}\left(\lambda_{c} \nabla \cdot u_{\mathrm{j}}^{s}+\alpha K^{a v} \nabla \cdot u_{\mathrm{j}}^{f}\right), \\
& p_{f}\left(u_{\mathrm{j}}\right)=-\alpha_{B} K^{a v} \nabla \cdot u_{\mathrm{j}}^{s}-K^{a v} \nabla \cdot u_{\mathrm{j}}^{f}, \\
& \mathcal{G}_{\mathrm{jk}}\left(u_{\mathrm{j}}\right)+i \omega \widetilde{\beta}_{\mathrm{jk}} \Pi_{\Gamma_{\mathrm{jk}}}\left(u_{\mathrm{j}}\right)=\mathcal{G}_{\mathrm{kj}}\left(u_{\mathrm{k}}\right)-i \omega \widetilde{\beta}_{\mathrm{jk}} \Pi_{\Gamma_{\mathrm{kj}}}\left(u_{\mathrm{k}}\right), \text { on } \Gamma_{\mathrm{jk}} \subset \Gamma_{\mathrm{j}}, \\
& \mathcal{G}_{\mathrm{kj}}\left(u_{\mathrm{k}}\right)+i \omega \widetilde{\beta}_{\mathrm{jk}} \Pi_{\Gamma_{\mathrm{kj}}}\left(u_{\mathrm{k}}\right)=\mathcal{G}_{\mathrm{jk}}\left(u_{\mathrm{j}}\right)-i \omega \widetilde{\beta}_{\mathrm{jk}} \Pi_{\Gamma_{\mathrm{jk}}}\left(u_{\mathrm{j}}\right), \text { on } \Gamma_{\mathrm{jk}} \subset \Gamma_{\mathrm{k}}, \\
& -\mathcal{G}\left(u_{\mathrm{j}}\right)=i \omega \mathcal{B} \Pi_{\Gamma_{\mathrm{j}}}\left(u_{\mathrm{j}}\right) \text { on } \Gamma_{\mathrm{j}} \cap \partial \Omega^{s} .
\end{aligned}
$$

In Eq. (27) the coefficient $g_{0}=1.5 \alpha_{\infty} \rho^{E} / \phi$ stands for the mass coupling coefficient; in it $\alpha_{\infty}=\phi^{-m^{c}}$, being the exponent $m^{c}$ the so called Archie's consolidation factor, is the structure or tortuosity factor. The first of these coefficients represents the inertial effects associated with dynamic interactions between solid and fluid phases, and is sometimes referred to as effective fluid inertia [Haines and Pride, 2006]. Notice that the coupling between electromagnetic and mechanical processes in this equation is expressed in the right hand side, involving the electrokinetic coupling coefficient $\mathcal{L}_{0}$. In the constitutive relations (28)-(29), $\tau_{l m}^{b}$ and $\epsilon_{l m}^{b}$ denote the two dimensional stress and strain tensors, $\lambda_{u}=K_{u}-\frac{2}{3} G^{f r}$ and the other coefficients have been defined in Section 2.2. Eqs. (30)-(31) express, in terms of Robin transmission conditions, the consistency conditions at the interior boundaries $\Gamma_{j k}$, meaning the continuity of the solid displacement, the normal component of the fluid displacements and the generalized stresses [Santos et al., 2005]. In these expressions, $\widetilde{\beta_{j k}}$ is a positive definite matrix [Santos et al., 2004b,a]. On the boundary of the domain $\Omega^{s}$ the first order ABC given by the Eq. (32) is employed; see the just mentioned references for details. In Eqs. (30)-(32) we have 
denoted

$$
\begin{aligned}
& \mathcal{G}_{\mathrm{j}}\left(u_{\mathrm{j}}\right)=\left(\tau\left(u_{\mathrm{j}}\right) \nu_{\mathrm{j}} \cdot \nu_{\mathrm{j}}, \tau\left(u_{\mathrm{j}}\right) \nu_{\mathrm{j}} \cdot \chi_{\mathrm{j}},-p_{f}\left(\left(u_{\mathrm{j}}\right)\right) \text { on } \Gamma_{\mathrm{j}},\right. \\
& \mathcal{G}_{\mathrm{jk}}\left(u_{\mathrm{j}}\right)=\left(\tau\left(u_{\mathrm{j}}\right) \nu_{\mathrm{jk}} \cdot \nu_{\mathrm{jk}}, \tau\left(u_{\mathrm{j}}\right) \nu_{\mathrm{jk}} \cdot \chi_{\mathrm{jk}},-p_{f}\left(\left(u_{\mathrm{j}}\right)\right) \text { on } \Gamma_{\mathrm{jk}},\right. \\
& \Pi_{\Gamma_{\mathrm{j}}}\left(u_{\mathrm{j}}\right)=\left(u_{\mathrm{j}}^{s} \cdot \nu_{\mathrm{j}}, u_{\mathrm{j}}^{s} \cdot \chi_{\mathrm{j}}, u_{\mathrm{j}}^{f} \cdot \nu_{\mathrm{j}}\right), \text { on } \Gamma_{\mathrm{j}}, \\
& \Pi_{\Gamma_{\mathrm{jk}}}\left(u_{\mathrm{j}}\right)=\left(u_{\mathrm{j}}^{s} \cdot \nu_{\mathrm{jk}}, u_{\mathrm{j}}^{s} \cdot \chi_{\mathrm{jk}}, u_{\mathrm{j}}^{f} \cdot \nu_{\mathrm{jk}}\right) \text { on } \Gamma_{\mathrm{jk}}, \\
& \mathcal{B}=\mathcal{R}^{1 / 2} \mathcal{D}^{1 / 2} \mathcal{R}^{1 / 2}, \text { where } \mathcal{D}=\mathcal{R}^{-1 / 2} \mathcal{H} \mathcal{R}^{-1 / 2},
\end{aligned}
$$

with

$$
\mathcal{R}=\left(\begin{array}{ccc}
\rho^{b} & 0 & \rho^{E} \\
0 & \rho^{b}-\frac{\rho^{E^{2}}}{g_{0}} & 0 \\
\rho^{E} & 0 & g_{0}
\end{array}\right), \quad \mathcal{H}=\left(\begin{array}{ccc}
\lambda_{c}+2 G^{f r} & 0 & \alpha K^{a v} \\
0 & G & 0 \\
\alpha_{B} K^{a v} & 0 & K^{a v}
\end{array}\right) .
$$

We can introduce now the iterative hybridized domain decomposed finite element procedure, mentioning different versions of this method have been previously employed to simulate wave propagation in saturated porous media with composite matrices [Santos et al., 2004b] and propagation of ultrasonic waves in media with patchy saturation [Santos et al., 2005]. Here a brief description of the method is given; for details the reader is encouraged to read these last references.

To approximate each component of the solid displacements a nonconforming finite element space is used; while the fluid displacements are approximated by the vector part of the Raviart-Thomas-Nedelec space of zero order [Nedelec, 1980]. Specifically, set $\theta(x)=x^{2}-$ $\frac{5}{3} x^{4}, R=[-1,1]^{2}$ and

$$
\begin{aligned}
& \varrho^{L}(x, z)=\frac{1}{4}-\frac{1}{2} x-\frac{3}{8}(\theta(x)-\theta(z)), \varrho^{R}(x, z)=\frac{1}{4}+\frac{1}{2} x-\frac{3}{8}(\theta(x)-\theta(z)), \\
& \varrho^{B}(x, z)=\frac{1}{4}-\frac{1}{2} z+\frac{3}{8}(\theta(x)-\theta(z)), \varrho^{T}(x, z)=\frac{1}{4}+\frac{1}{2} z+\frac{3}{8}(\theta(x)-\theta(z)) ;
\end{aligned}
$$

we define $\mathcal{Y}(R)=\operatorname{Span}\left\{\varrho^{L}, \varrho^{R}, \varrho^{B}, \varrho^{T}\right\}$ and $\mathcal{W}(R)=\mathcal{Y}(R) \times \mathcal{Y}(R)$. Also, if $\varphi^{L}(x)=$ $-1+x, \varphi^{R}(x)=x, \varphi^{B}(z)=-1+z, \varphi^{T}(z)=z$, set

$$
\mathcal{Z}(R)=\operatorname{Span}\left\{\left(\varphi^{L}(x), 0\right),\left(\varphi^{R}(x), 0\right),\left(0, \varphi^{B}(z)\right),\left(0, \varphi^{T}(z)\right)\right\},
$$

and the finite element spaces $\mathcal{W}_{j}^{h}$ and $\mathcal{Z}_{j}^{h}$ are defined as usual by scaling and translating to the element $\Omega_{j}$. Notice that in each domain of the finite element partition there exist twelve unknowns, four for each solid displacement component, and two for each component of the fluid displacement. A scheme of the degrees of freedom for this space of nonconforming finite element is illustrated in Fig.3(b). The hybridization implies also here the introduction of 
Lagrange multipliers, this time associated to generalized forces at the midpoints $\gamma_{j k}$ on the interelement boundaries $\Gamma_{j k}$, in the sense that $\lambda_{j k} \sim \mathcal{G}\left(u_{j}\right)\left(\gamma_{j k}\right)$ [Santos et al., 2005]. They belong to the following space of functions defined on the interior interfaces:

$$
\mathcal{L}=\left\{\lambda:\left.\lambda\right|_{\Gamma_{\mathrm{jk}}}=\lambda_{\mathrm{jk}} \in\left[P_{0}\left(\Gamma_{\mathrm{jk}}\right)\right]^{3}=\mathcal{L}_{\mathrm{jk}}^{h} \forall \mathrm{j}, \mathrm{k}\right\}
$$

Setting initial values $\left(u_{\mathrm{j}}^{s, h, 0}, u_{\mathrm{j}}^{f, h, 0}, \lambda_{\mathrm{jk}}^{h, 0}\right)$ the iterative algorithm reads:

Find $\left(u_{j}^{s, h, n+1}, u_{j}^{f, h, n+1}, \lambda_{j k}^{h, n+1}\right) \in \mathcal{W}_{j}^{h} \times \mathcal{Z}_{j}^{h} \times \mathcal{L}_{j k}^{h}$ such that

$$
\begin{aligned}
& -\omega^{2}\left(\rho^{b} u_{j}^{s, h, n+1}+\rho^{E} u_{j}^{f, h, n+1}, v^{s}\right)_{\Omega_{j}}-\omega^{2}\left(\rho^{E} u_{j}^{s, h, n+1}+g_{0} u_{j}^{s, h, n+1}, v^{f}\right)_{\Omega_{j}} \\
& +i \omega\left(g_{0} u_{j}^{f, h, n+1}, v^{f}\right)_{\Omega_{j}}+\sum_{l m}\left(\tau_{l m}^{b}\left(v_{j}^{h, n+1}\right), \varepsilon_{l m}^{b}\left(v^{s}\right)\right)_{\Omega_{j}} \\
& -\left(p_{f}\left(u_{\mathrm{j}}^{h, n+1}\right), \nabla \cdot v^{f}\right)_{\Omega_{\mathrm{j}}}+\left\langle i \omega \mathcal{B} \Pi_{\Gamma_{\mathrm{j}}}\left(u_{\mathrm{j}}^{s, h, n+1}\right), \Pi_{\Gamma_{\mathrm{j}}}(v)\right\rangle_{\Gamma_{\mathrm{j}} \cap \partial \Omega^{s}} \\
& +\sum_{\substack{\mathrm{k} \\
\Gamma_{\mathrm{jk}} \cap \partial \Omega^{s}=\phi}}\left\langle i \omega \widetilde{\beta}_{j \mathrm{k}} \Pi_{\Gamma_{j \mathrm{k}}}\left(u_{\mathrm{j}}^{h, n+1}\right), \Pi_{\Gamma_{j \mathrm{k}}}(v)\right\rangle_{\Gamma_{\mathrm{jk}}}=\left(\frac{\eta}{k_{0}} \mathcal{L}_{0} E_{\mathrm{j}}, v^{f}\right)_{\Omega_{j}} \\
& -\sum_{\Gamma_{j \mathrm{k}}^{\mathrm{k}} \cap \partial \Omega^{s}=\phi}\left\langle i \omega \widetilde{\beta}_{j \mathrm{k}} \Pi_{\Gamma_{\mathrm{kj}}}\left(u_{\mathrm{k}}^{h, *}\right), \Pi_{\Gamma_{j \mathrm{k}}}(v)\right\rangle_{\Gamma_{\mathrm{jk}}}+\sum_{\Gamma_{j \mathrm{k}} \cap \partial \Omega^{s}=\phi}\left\langle\lambda_{\mathrm{kj}}^{h, *}, \Pi_{\Gamma_{j \mathrm{k}}}(v)\right\rangle_{\Gamma_{j \mathrm{k}}} \\
& \lambda_{j \mathrm{k}}^{h, n+1}=\lambda_{\mathrm{kj}}^{h, *}-i \omega \widetilde{\beta}_{\mathrm{jk}}\left[\Pi_{\Gamma_{j \mathrm{k}}}\left(u_{\mathrm{j}}^{h, n+1}\right)+\Pi_{\Gamma_{\mathrm{kj}}}\left(u_{\mathrm{k}}^{h, *}\right)\right]\left(\gamma_{\mathrm{jk}}\right) \text {. }
\end{aligned}
$$

The same different choices for selecting the meaning $*$ present the iterative scheme Eqs. (23)(25) are available in this case. Whatever the decision, to solve Eqs. (43)-(44) the calculations are more involved than in the former case. For example, if the chess-board implementation of the Red-Black scheme is selected, equation (43) implies that in each iteration and for each one of the elements into which the domain $\Omega^{s}$ is divided a $12 \times 12$ linear system of equations needs to be solved.

Notice also that the iteration parameter $\widetilde{\beta}_{\mathrm{jk}}$ is chosen as the average $\frac{1}{2}\left(\mathcal{B}_{\mathrm{j}}+\mathcal{B}_{\mathrm{k}}\right)$, where $\mathcal{B}$ is the matrix appearing in the absorbing boundary conditions. Furthermore, notice that the Lagrange multipliers, associated to generalized forces on the inter-element boundaries $\Gamma_{j k}-$ but evaluated at the mid-points $\gamma_{j k}$ - are calculated in each element by (44), which represents twelve scalar equations. Thus, for each frequency $\omega$ this algorithm reduces to solve in each iteration and for each one of the elements into which $\Omega^{s}$ is divided, a linear system of twelve unknowns (eight from the solid an four from the fluid) plus twelve scalar equations to get the Lagrange multipliers.

As a final remark, we mention that the spacetime solution is obtained by solving Eqs. (43)-(44) for a finite number of frequencies and taking the inverse Fourier transform. Of course, this comment is valid also for the iterative procedure used to get the electric field. 


\section{Parallel implementation}

For the implementation of the parallel code we used the MPI standard [Pacheco, 2011]. The most efficient way to perform the calculations is to assign to each processor, as close as possible, the same number of unknowns [Alumbaugh et al., 1996]. In our case, that means to assign the same number of subdomains $\Omega_{j}$ to each processor. If the load of the processors is not balanced, some will remain idle while others are still computing, reducing the efficiency of the algorithm. In order to fix ideas, let us work with nine processors (Fig5a), or three processors (Fig5b). Each one runs exactly the same copy of the program, and gets the input data from a single data file. Local variables are converted to global when necessary within the code; we preferred this strategy to splitting the input file in multiple ones to be read by each processor [Newman and Alumbaugh, 1997]. In Fig. 5 we display, by using different colors, the portion of the computational domain $\Omega$ assigned to each processor; the solid lines represent the virtual boundaries among them. Naturally, it is possible to do this assignment in different ways, we chose to display a very simple one for the sake of clarity. The processor $\mathbf{P}_{\mathbf{0}}$ solves only in red (Fig5a) or green (Fig5b) regions, and simultaneously the other processors perform their calculations in their respective regions.

The time needed to get the solution is usually longer than one-ninth (Fig5a) or one-third (Fig5b) of the time with a serial code on one processor (assuming that processors of the same kind are used). This happens because in each iteration 'adjacent' processors must interchange information, so that the right hand sides of the elements situated on the borders of the region corresponding to each processor is correctly set: In Fig.5 these regions are signaled with stronger colours and delimited with dashed lines; they also show the processor number involved in the data exchange; e.g., in Fig.5a 0-3 indicates the twelve elements, six assigned to processor $\mathbf{P}_{\mathbf{0}}$ (blue) and six assigned to processor $\mathbf{P}_{\mathbf{3}}$ (green) which must be selected to interchange data between them. The information to be transmitted involves all the coefficients building the approximate solutions $\left(E_{j}^{n}, H_{j}^{n}, \ell_{j \mathrm{k}}^{n}\right)$ for Maxwell's equations, $\left(u_{j}^{s, n}, u_{j}^{f, n}, \lambda_{j \mathrm{k}}^{n}\right)$ for Biot's equations. Clearly, the same is valid for all the other regions; the interchange of information among processors is performed simultaneously, once Eqs. (23)-(25) (Maxwell) (43)-(44) (Biot) are solved in all nine (Fig. 5a) domains or three (Fig. 5b) domains.

We asserted that these domain decomposed algorithms are naturally rendered parallel not only because of the description given above, but also due to the fact that the amount of data to be transferred is not large. As sketched in Fig.5a and Fig. 5b the strong coloured re- 
gions lay on only a single finite element width, because, as we explained above, the right hand side of the iterative procedures involve only nearest neighbours.

\section{Case study: $\mathrm{CO}_{2}$ sequestration}

Although previous field results in electroseismics employed surface sources and surface receivers [Thompson et al., 2007], in a more recent report on $\mathrm{CO}_{2}$ geological storage monitoring, synthetic and field geoelectrical methods were applied to study possible gas migration [Kiessling et al., 2010]. Moreover Ishido et al. [2013] have numerically investigated the application of self potential methods to monitor the migration of $\mathrm{CO}_{2}$ sequestrated into saline aquifers, concluding that the used methods are effective for sensing the approach of $\mathrm{CO}_{2}$ to the well casings deep within the subsurface. On the other hand, Kim et al. [2013] have shown that seismics was useful to detect $\mathrm{CO}_{2}$ saturation below $15 \%$ and that electrical resistivity was useful to detect $\mathrm{CO}_{2}$ saturation above $15 \%$.

Inspired by these results, we analyse the behaviour of seismic responses to an electromagnetic source deployed in a well, locating it beneath a $\mathrm{CO}_{2}$ plume, trapped by an overlying seal layer, as we depict in Fig. 4. We simulate a time-lapse monitoring scenario, by taking three different situations; the first one when no $\mathrm{CO}_{2}$ has been pumped into the subsurface, and therefore its saturation is $0 \%$, a second one with a $\mathrm{CO}_{2}$ saturation of $35 \%$, and a third one with a $\mathrm{CO}_{2}$ saturation of $60 \%$. We consider a PSVTM case, so, in order to get the appropriate fields, the selected electromagnetic source is a magnetic dipole of infinite length in the strike direction ( $y$-axis), located right beneath a $\mathrm{CO}_{2}$ plume at $220 \mathrm{~m}$ depth. Its expression, to be set in Eq. (23) is $J^{m}=-i \omega \mu \widehat{S} I(\omega) \delta\left(x-x_{s}\right) \delta\left(z-z_{s}\right) \check{y}$; here $\widehat{S}$ is the area of the current loop, $I(\omega)$ is the current and $\left(x_{s}, z_{s}\right)$ is the center of the loop, assumed to be the source location. Seismic receivers are set in two different uncased wells, located at $10 \mathrm{~m}$ to the right (Well \#1) and $100 \mathrm{~m}$ to the left (Well \#2) of the horizontal position of the electromagnetic source. Notice that no conversions at the well walls are considered in our approach. This effect has been studied by [Hu and Liu, 2002], who analyzed the converted electric field during acoustoelectric logging. Surface receivers are also set, ranging from $300 \mathrm{~m}$ to the left to $300 \mathrm{~m}$ to the right of $x_{s}$, separated $4 \mathrm{~m}$ from each other. The time signature of the source is a Ricker wavelet with peak frequency of $60 \mathrm{~Hz}$; its peak amplitude in time is located at $t=0.16 \mathrm{~s}$.

This source is Fourier transformed, and 200 equally spaced samples $I(\omega)$ are used in the calculations; each one of them is used in the right hand side of Ampere-Maxwell's equations (23) in the above described PSVTM algorithms. Once all the results in the space-frequency 
domain are obtained, they are inverse Fourier transformed to get the space-time responses that we show and analyse below.

The physical properties of the top layer, seal layer, bottom layer and $\mathrm{CO}_{2}$ plume are derived from basic parameter values given in Tables 1 and 2 using the different effective properties described in Section 2. Notice that the effective fluid properties in the $\mathrm{CO}_{2}$ plume are calculated assuming that the $\mathrm{CO}_{2}$ is in its supercritical state, as is usually pumped into the subsurface [Kiessling et al., 2010; Cairns et al., 2012]. Although the depth at which we situated the reservoir is not deep enough to create the conditions for the $\mathrm{CO}_{2}$ to remain supercritical [Kazemeini et al., 2010], we retain the mentioned depth value to keep a reasonable computational cost, because of the size of the model. Note that the following analysis would remain exactly the same if we increased the depth of the bottom of the top layer as much as necessary to reach the pressure and temperature conditions for the $\mathrm{CO}_{2}$ to be in supercritical state.

Concerning the calculation of the bulk electrical conductivity by means of Eq. (12) in the region occupied by the plume, we mention here that we consider the electrical conductivity of carbon dioxide negligible compared to that of the brine partially saturating it. The presence of $\mathrm{CO}_{2}$ diminishes the bulk electrical conductivity as it would happen if air is present; however in supercritical state the reduction is not so strong as it it would be if the $\mathrm{CO}_{2}$ is gaseous [Borner et al., 2013]. As a final remark concerning the computation of the electrokinetic coupling $L_{0}$ in the plume, we want to mention that when $\mathrm{CO}_{2}$ is pumped into a reservoir a small portion dissolves in water [Carcione et al., 2006b; Wang et al., 2013b], forming weak carbonic acid which reacts with the present dissolved salt ions [Darwish and Hilal, 2010]. This process alters the $\zeta$ potential [Moore et al., 2004], which in turn changes the electrokinetic coupling; in the present work the $\zeta$ potential does not depend on the presence of carbon dioxide. However, the latter is taken into account, as described above, by making $L_{0}$ saturation dependent. We assumed that the electrokinetic coupling is changed when the amount of $\mathrm{CO}_{2}$ is increased and water expelled, as it changes when water-saturation is decreased, replaced by air.

\subsection{Well gathers}

Let us now turn our attention to our results; in Fig. 6 we display the x-component of the solid acceleration records of the receivers located in a portion of well \#1, between $100 \mathrm{~m}$ depth and $280 \mathrm{~m}$ depth, before pumping $\mathrm{CO}_{2}$ into the reservoir (Fig. 6(a)) and when the carbon dioxide saturation of the plume reached a $35 \%$ saturation (Fig. 6(b)). The ES source is a magnetic dipole located at $220 \mathrm{~m}$ depth and originates the seismic signals from the interfaces be- 
tween different porous media due to the electroosmotic coupling [Pride, 1994; Pride and Garambois, 2005; Haines and Pride, 2006]. In the Fig. 6(a), P and SV waves are clearly observed. They travel upwards and downwards from the seal layer and their velocities can be calculated by measuring the slopes; they are consistent with their values obtained from the dispersion relations. SV waves are well identified in the x-component for shallow and deep receivers. In Fig. 6(b) it is possible to notice changes in the character of the signals by the presence of the partially saturated $\mathrm{CO}_{2}$ plume. The receivers located between $210 \mathrm{~m}$ and $220 \mathrm{~m}$ depth, i.e., the thickness of the plume, get a stronger signal which also lasts longer, due possible to reflections on the bases of the seal layer and plume respectively. The polarization change in the $\mathrm{x}$-component of the solid acceleration observed at the depth at which the electromagnetic source is located is consistent with the fact that the $\mathrm{x}$-component of the electric field, being tangent to the electric current circulating in the wire loop, changes its sign at $z=z_{s}$.

In Fig. 7 we display the z-component of the solid acceleration records, also for the receivers located in well \#1, and for the same depth interval as in the previous figure. We observe also here that the presence of the $\mathrm{CO}_{2}$ plume generates stronger signals for receivers located at its same depth interval, somehow "focusing" the converted seismic signals within the plume. In the case (a) of both figures, the signals are reinforced under the seal layer due to the influence of top and base of it.

Turning now our attention to the comparison of the relative amplitudes of the converted signals, we show, for both solid acceleration components, single traces measured at $190 \mathrm{~m}$ depth, i.e. above the seal layer in Fig. 8, and at $230 \mathrm{~m}$ depth, i.e. below the $\mathrm{CO}_{2}$ plume (see Fig. 7), for the three $\mathrm{CO}_{2}$ concentrations we are considering. It can be observed in all cases that the response for the $0 \%$ saturation is the weakest one and that the $35 \%$ saturation case is the strongest. The fact that the amplitude of the traces corresponding to the 35\% saturation case is stronger than the ones corresponding to the $60 \%$ saturation case is compatible with the behaviour of the $\mathcal{C}\left(S_{w}\right)$ function, because in the saturation interval considered, it grows with the water saturation ( $40 \%$ to $65 \%$ of water, see Fig. 1), i.e., it diminishes with $\mathrm{CO}_{2}$ saturation (from $35 \%$ to $60 \%$ of $\mathrm{CO}_{2}$ ). Therefore, the electrokinetic coupling coefficient Eq. (13), and correspondingly the amplitude of the seismic source is smaller for the $60 \% \mathrm{CO}_{2}$ case than for the $35 \%$ $\mathrm{CO}_{2}$. Note that the difference of amplitude in the traces is bigger than the corresponding in $\mathcal{C}\left(S_{w}\right)$, due to the factor $S_{w}^{n}$ in this equation. It can also be observed that the amplitude of the traces measured below the plume, see Fig.7, are larger than the ones located above the seal layer, see Fig.6, for all $\mathrm{CO}_{2}$ concentrations and both acceleration components, because pre- 
cisely of the presence of the seal, which partially reflects the incident waves impinging into its base from below, due to the contrast in mechanical properties between them.

Finally in Fig. 10 we compare, for a single receiver located at $216 \mathrm{~m}$ depth, i.e. level with the plume, the amplitudes of the traces, for both acceleration components, recorded at well \#1 and well \#2. It can be clearly observed how the amplitude of the signal decays, because both of spherical divergence and viscoelasticity as it travels out of the source since the well \#1 is situated at $10 \mathrm{~m}$ from the source whereas the well \#2 is situated at $100 \mathrm{~m}$ from the source.

\subsection{Surface gathers}

Let us now consider the responses measured by the surface accelerometers, depicted in Fig. 11 for the z-component. Fig. 11(a) corresponds to the model without $\mathrm{CO}_{2}$, while Fig. 11(b) show the results for the $35 \%$ saturation case. In the former case, two interface responses (IR) are observable. These IR arrive at the same time on surface receivers and are shown as horizontal arrivals in Figure 11(a). The topmost one, namely $\mathrm{IR}_{1}$, corresponds to the conversion of the electromagnetic signal hitting the surface (almost) at the same time as the magnetic dipole is turned on at $220 \mathrm{~m}$ depth; recall that the Ricker wavelet we are using as the source signature is not centred at $t=0 \mathrm{~s}$, but it has a time delay of $t=0.016 \mathrm{~s}$. Of course, this IR conveys no information of the subsurface structure. The other interface response, labelled $\mathrm{IR}_{2}$ in the figure, is originated at the interfaces defined by base and top of the seal layer; notice that they are not resolved in the measured traces. The fact that the two IRs are not observable in Fig. 11(b) is just because the amplitude of hyperbolic-shaped signal is much higher than the one corresponding to the no $\mathrm{CO}_{2}$ case. We show that this is indeed the situation in Fig. 12, where we have plotted a single trace from the surface gather of both $\mathrm{CO}_{2}$ concentrations here considered, located at $260 \mathrm{~m}$ offset; the arrival times of both interface responses and the upwards travelling signal are at this offset easily individualized. The topmost interface response is, as expected, exactly the same for both situations, while the time arrivals of the second one for the two saturation cases do differ; this happens because at $35 \% \mathrm{CO}_{2}$ saturation there is a new interface response originated at the plume base, located at $220 \mathrm{~m}$ depth, which constructively interferes with the ones arising at the top and bottom interfaces of the seal layer. Finally, it can be noticed that the amplitude of the hyperbola is much bigger for the case with partial carbon dioxide saturation than for the case at zero saturation. 
The other relevant feature, which does contain information about the carbon dioxide content, as we explain below, is the hyperbolic-shaped signal with vertex at about $0.046 \mathrm{~s}$.

As we described when explaining the well gathers, this signal is due to the electroosmotic coupling at the electromagnetic source position, spreads outwards from it and hits the seal layer and $\mathrm{CO}_{2}$ plume, generating multiple reflections inside them. Some of this reflected waves travels towards the surface, and are detected by the receivers there.

That this signal contains information of the $\mathrm{CO}_{2}$ content can be justified as follows: on one hand, the amplitude of the signals measured for the 35\% saturation case is bigger than for the $0 \%$ saturation case, as we have just shown. On the other hand, in Fig. 13 we depict surface traces recorded at $20 \mathrm{~m}$ offset, before pumping $\mathrm{CO}_{2}$ into the reservoir and with $\mathrm{CO}_{2}$ saturations of $35 \%$ and $60 \%$. It can be here clearly seen that the amplitudes depend on the saturation in the plume, and that the amplitude of the trace for the no carbon dioxide case is weaker than the other ones, which make the IRs, detectable in the former case, invisible for the latter cases. Yet another point to be noticed is that the amplitude of the traces at the surface is about one order of magnitude weaker than the ones recorded at depth.

\subsection{Parallel performance}

In order to analyse the parallel performance of our algorithm, we compute the time needed to reach convergence by the iterative algorithms described by (23)-(25) and (43)-(44) for a single frequency and different number of cores, using the MDD implementation. We run the model previous to the $\mathrm{CO}_{2}$ injection and select the source peak frequency. The number of iterations to reach convergence is not a function of the number of computing cores; i.e., the numerical procedure for Maxwell's equations ends at the same iteration number irrespective of the number of cores employed. The same happens for Biot's equations, but of course, the number of iterations to reach the convergence threshold it is not the same as Maxwell's. In our examples the chosen convergence threshold, being the value that the added relative error between successive solutions for all unknowns and for all the finite elements must reach, was set to $10^{-3}$.

In Table 3 we display, for two different meshes, namely a "small" one containing 2048 $\times 1048$ elements $\left(\approx 3.56 \times 10^{7}\right.$ unknowns $)$ and a "big" one containing $4096 \times 2048$ elements $\left(\approx 1.43 \times 10^{8}\right.$ unknowns $)$ an analysis of the performance of our numerical algorithm in a parallel computing environment. We display, for each mesh and as a function of the number of computing cores, the computing time, the ratio of the computing time with one core to the computing time with $N$ cores, i.e., the so called "speedup" $\mathcal{S}_{p}=T_{1} / T_{N}$, and finally, 
we display the so called "parallel efficiency" $\mathcal{E}_{p}=\mathcal{S}_{p} / N$ [Foster, 1995]. If the parallel algorithm was perfect, the speedup $\mathcal{S}_{p}$ would be a linear function of the number of computing cores; this is not what happens, mainly because the cores must interchange information to perform their computations, as explained in section 4 Parallel implementation. From the point of view of the parallel efficiency, $\mathcal{E}_{p}=1$ would mean a perfectly efficient parallel algorithm; the reason of its decay with increasing number of computing cores is the same as before: the overhead due to the data transmission among processors. It is worth to mention that for the big mesh, the computation with four cores show superlinear behaviour, or parallel efficiency greater than one. Although it has been argued that this is not possible [Faber et al., 1986], it has been later demonstrated that this behaviour can be observed [Agrawal et al., 1994; Shan, 2002] if resources are used more efficiently, for example by reducing the RAM access time.

Notice also that the efficiency decays faster when more than 64 cores are used. This happens because the cluster we employed consists of nodes containing this core number, being the nodes interconnected through an InfiniBand network. Then, communication among cores of a single node is faster than when all cores belonging to two or four nodes have to transmit data among them.

It is also worth noticing that the efficiency decay is slower for the bigger mesh, i.e., our numerical algorithm is scalable [Foster, 1995; Pacheco, 2011]. Of course, the absolute computing time will still decay while increasing the number of cores, but if the size of the problem is not increased, the efficiency of the computation will decrease.

\section{Conclusions}

We have implemented a set of domain decomposed iterative finite element algorithms to approximate the solution to the Pride's equations. These algorithms can be used to model the two dimensional PSVTM and SHTE modes of both electroseismics and seismoelectrics; swapping between both techniques implies in our numerical formulation just to choose the nature of the employed source, and the order in which Maxwell's and Biot's equations are solved. In this chapter we have modelled a time lapse monitoring of a $\mathrm{CO}_{2}$ deposition site by means of PSVTM electroseismics. Our results suggest that the wells used to pump carbon dioxide into the subsurface could be used to set magnetic dipoles as sources and accelerometers as recording devices, and the measured signals would be sensitive to the $\mathrm{CO}_{2}$ concentration. Moreover, this setting would avoid the necessity of filtering the coseismic signal, a well known difficulty arising when both sources and receivers are set on the surface. 
666

667

668

669

From the strictly numerical point of view, we have demonstrated that our algorithms can handle large number of unknowns, and proved to be scalable. We deem that these characteristics make our code a competitive one as a modelling tool both in electroseismics and seismoelectrics. 


\begin{tabular}{lr}
\hline Common model parameters \\
\hline$m^{c}$ & 1.85 \\
$n$ & 1.85 \\
$K^{s, \text { sand }}[\mathrm{GPa}]$ & 35 \\
$K^{s, \text { silt }}[\mathrm{GPa}]$ & 34 \\
$K^{s, \text { clay }}[\mathrm{GPa}]$ & 12.3 \\
$G^{s, \text { sand }}[\mathrm{GPa}]$ & 44 \\
$G^{s, \text { silt }}[\mathrm{GPa}]$ & 43 \\
$G_{s, \text { clay }}[\mathrm{GPa}]$ & 15.6 \\
$\rho^{s, \text { sand }}\left[\mathrm{Kg} / \mathrm{m}^{3}\right]$ & 2600 \\
$\rho^{s, \text { silt }}\left[\mathrm{Kg} / \mathrm{m}^{3}\right]$ & 2600 \\
$\rho^{s, \text { clay }}\left[\mathrm{Kg} / \mathrm{m}^{3}\right]$ & 2580 \\
$D_{s, \text { sand }}[\mathrm{m}]$ & $8 \times 10^{-5}$ \\
$D_{s, \text { silt }}[\mathrm{m}]$ & $1 \times 10^{-5}$ \\
$D_{s, \text { clay }}[\mathrm{m}]$ & $5 \times 10^{-7}$ \\
$K^{w}[\mathrm{GPa}]$ & 2.25 \\
$\eta^{w}[\mathrm{~Pa} . \mathrm{s}]$ & $1 \times 10^{-3}$ \\
$\rho^{w}\left[\mathrm{Kg} / \mathrm{m}^{3}\right]$ & 1000 \\
$\varepsilon^{w}[\mathrm{~F} / \mathrm{m}]$ & $80 \varepsilon_{0}$ \\
$T$ [K] & 298 \\
\hline & \\
& \\
&
\end{tabular}

Table 1. Values of model parameters used in the present work. Those not shown in this table can be ob- 
Layer parameters

\begin{tabular}{|c|c|c|c|}
\hline Parameter & Top Layer & Seal & Bottom Layer \\
\hline$\gamma_{\text {sand }}[-]$ & 0.5 & 0.3 & 0.7 \\
\hline$\gamma_{\text {silt }}[-]$ & 0.4 & 0.45 & 0.25 \\
\hline$\gamma_{\text {clay }}[-]$ & 0.1 & 0.25 & 0.05 \\
\hline$\phi[-]$ & 0.15 & 0.2 & 0.33 \\
\hline$C_{0}[\mathrm{~mol} / \mathrm{L}]$ & $1 . \times 10^{-3}$ & 4. $\times 10^{-2}$ & 4. $\times 10^{-1}$ \\
\hline$K^{\mathrm{CO}_{2}}[\mathrm{~Pa}]$ & - & - & $2.5 \times 10^{7}$ \\
\hline$\eta^{C O_{2}}[$ Pa.s $]$ & - & - & $1.5 \times 10^{-5}$ \\
\hline$\rho^{C O_{2}}\left[\mathrm{Kg} / \mathrm{m}^{3}\right]$ & - & - & 505 \\
\hline
\end{tabular}

Table 2. Dissimilar model parameters for the top, seal and bottom layers. The $\mathrm{CO}_{2}$ values are used to obtain, together with the water corresponding ones, effective fluid parameters for the $\mathrm{CO}_{2}$ plume, as explained in Section 2. 


\begin{tabular}{|c|c|c|c|c|c|c|}
\hline \multicolumn{7}{|c|}{ Parallel performance } \\
\hline & \multicolumn{3}{|c|}{ Mesh } & \multicolumn{3}{|c|}{ Mesh } \\
\hline & \multicolumn{3}{|c|}{$2048 \times 1024$} & \multicolumn{3}{|c|}{$4096 \times 2048$} \\
\hline \# of Cores & Time $[\mathrm{s}]$ & $\mathcal{S}_{p}$ & $\mathcal{E}_{p}$ & Time $[\mathrm{s}]$ & $\mathcal{S}_{p}$ & $\mathcal{E}_{p}$ \\
\hline 1 & 12956 & 1 & 1 & 57572 & 1 & 1 \\
\hline 4 & 3252 & 3.98 & 0.99 & 13581 & 4.23 & 1.05 \\
\hline 16 & 1171 & 11.06 & 0.69 & 5034 & 11.43 & 0.71 \\
\hline 64 & 392 & 33.05 & 0.52 & 1600 & 35.98 & 0.56 \\
\hline 128 & 288 & 44.98 & 0.35 & 1016 & 56.67 & 0.44 \\
\hline 256 & 320 & 40.49 & 0.16 & 948 & 60.73 & 0.24 \\
\hline
\end{tabular}

Table 3. Computation times, speedup and parallel efficiency when solving a single frequency of the PSVTM algorithm, MDD implementation, for the model without $\mathrm{CO}_{2}$. Two different discretizations are considered, one involving $2048 \times 1024$ finite elements, i.e., approximately $3.56 \times 10^{7}$ unknowns, the other one involving $4096 \times 2048$ finite elements, i.e., approximately $1.43 \times 10^{8}$ unknowns. 
Allegre saturation function

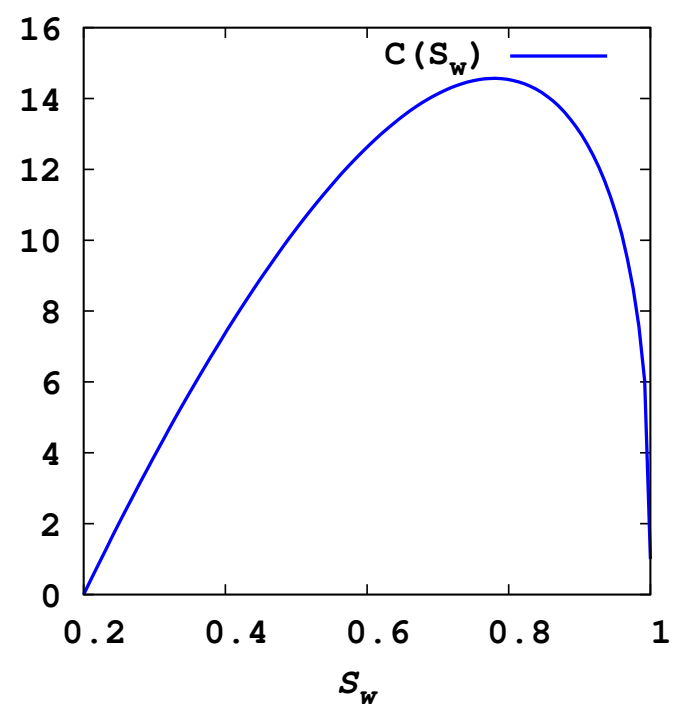

Figure 1. The saturation function $\mathcal{C}\left(S_{w}\right)$ employed to model the saturation dependent behaviour of the electrokinetic coupling coefficient $L_{0}$. 
(a)

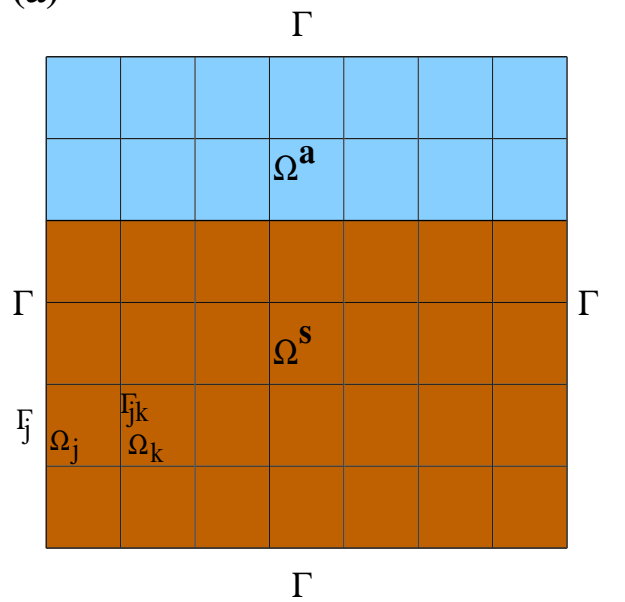

(b)



Figure 2. Electromagnetic equations case. (a) The computational domain $\Omega=\Omega^{a} \cup \Omega^{s}$ integrating air and subsurface, with external boundaries $\Gamma_{j}$ and internal boundaries $\Gamma_{j k}$. (b) Scheme for the five degrees of freedom associated with each element, four to the electric field and one to the magnetic field. 
(a)

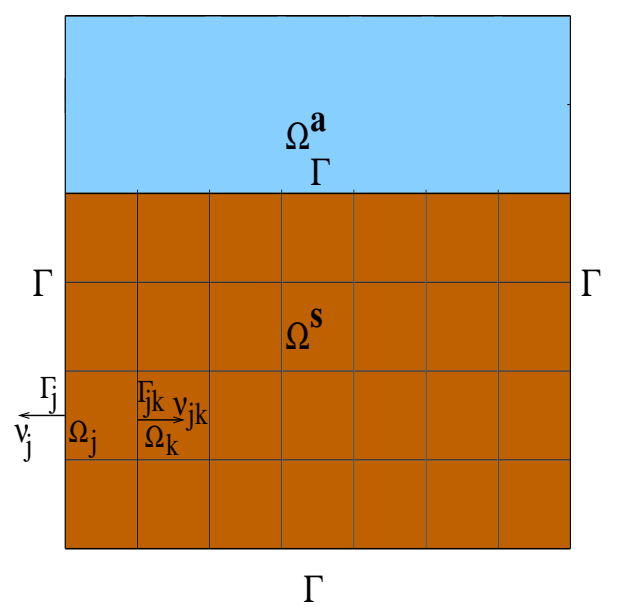

(b)

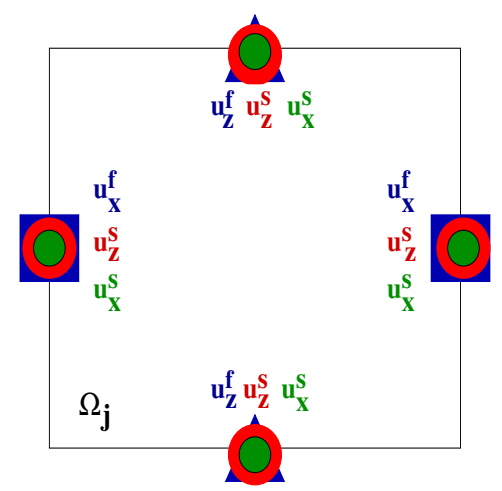

684

Figure 3. Biot's equations case. (a) The computational domain is only the subsurface $\Omega=\Omega^{s}$, with external boundaries $\Gamma_{j}$ and internal boundaries $\Gamma_{j k}$. The outer normals $\nu j$ and $\nu_{j k}$ are also indicated. (b) Scheme for the twelve degrees of freedom associated with each element, eight to the solid displacements and four to the fluid displacements. 


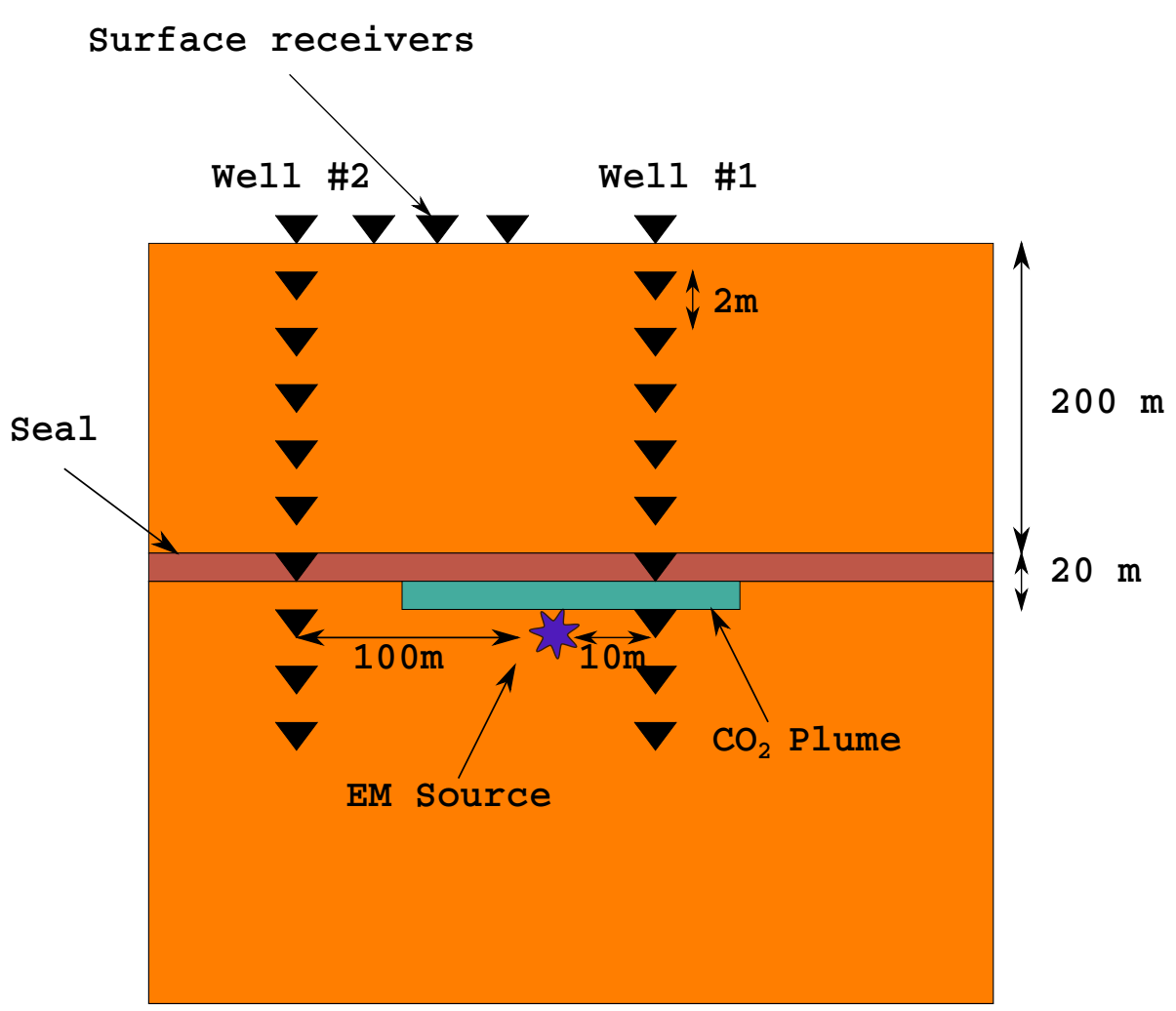

Figure 4. The $\mathrm{CO}_{2}$ geological deposition model. The electromagnetic source is at $220 \mathrm{~m}$ depth, below the $\mathrm{CO}_{2}$ plume, whose top is located at $210 \mathrm{~m}$ and base at $220 \mathrm{~m}$ (being the $\mathrm{CO}_{2}$ in supercritical state). The seismic receivers are on the surface and in two wells. 
(a)

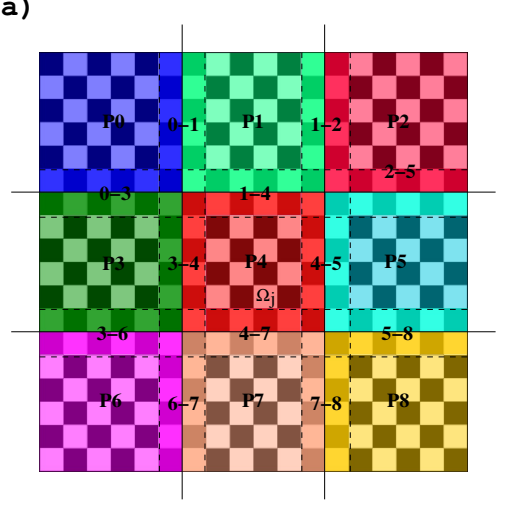

(b)

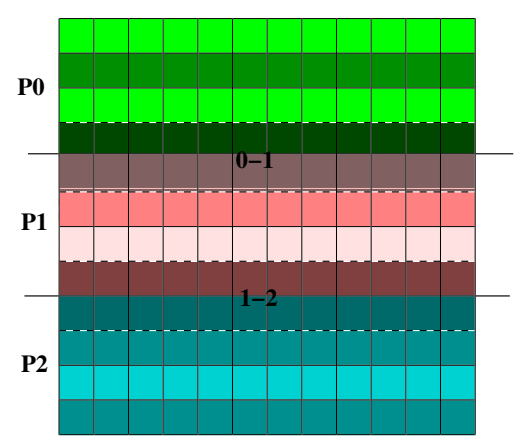

Figure 5. Each one of the displayed figures involves two layers, namely bottom layer and top layer. The former depicts the finite element partition, and domain decomposition of the computational domain $\Omega$ : (a) The MMD scheme, (b) The SDD scheme. The latter (coloured) shows the distribution of the computational domain according to the selected DD scheme: (a) nine computing cores, (b) three computing cores. 
Well \#1 - Acceleration Traces, $\mathrm{x}$ component
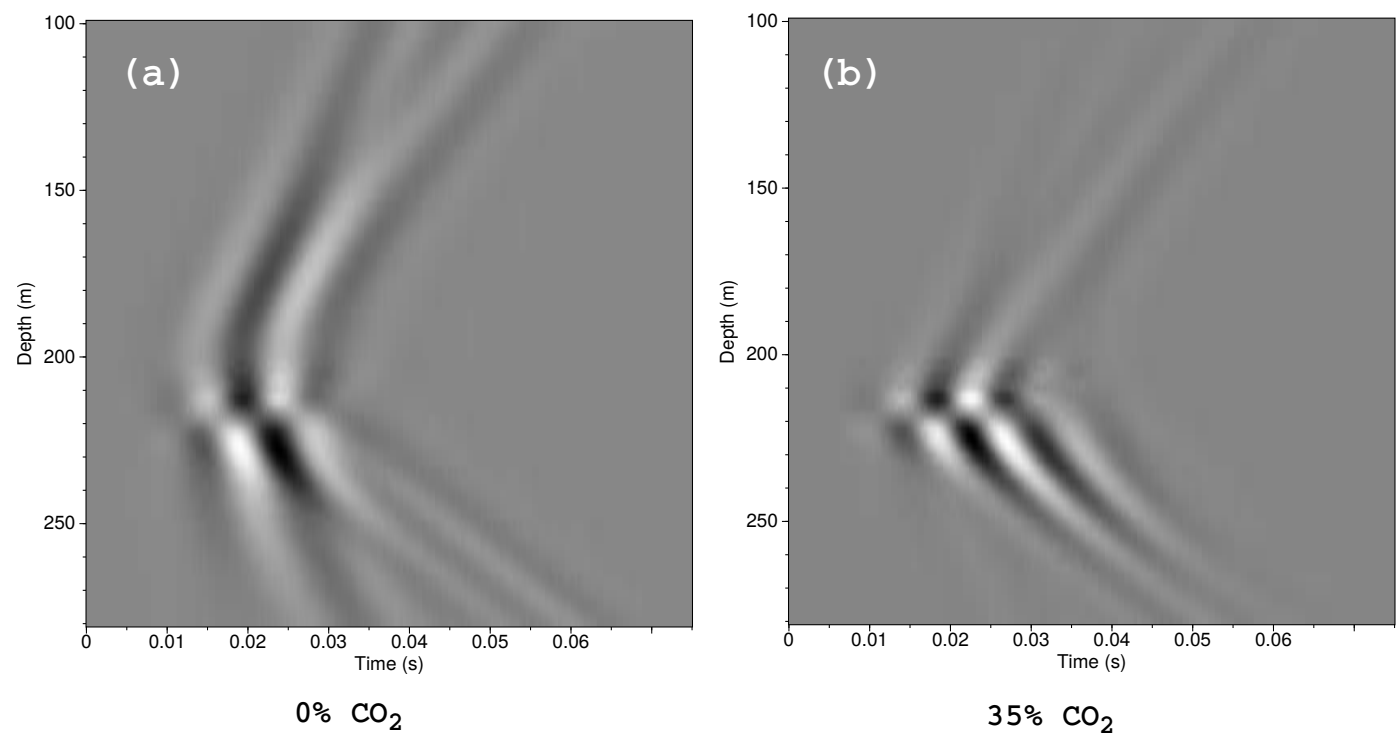

Figure 6. Well \#1 $\mathrm{x}$-component acceleration gather, before $\mathrm{CO}_{2}$ pumping (a), and when $\mathrm{CO}_{2}$ saturation reaches $35 \%$. The electromagnetic source is at depth $220 \mathrm{~m}$ just below the $\mathrm{CO}_{2}$ plume which is between 210 and $220 \mathrm{~m}$ depth. 


\section{Well \#1 - Acceleration Traces, $\mathrm{z}$ component}
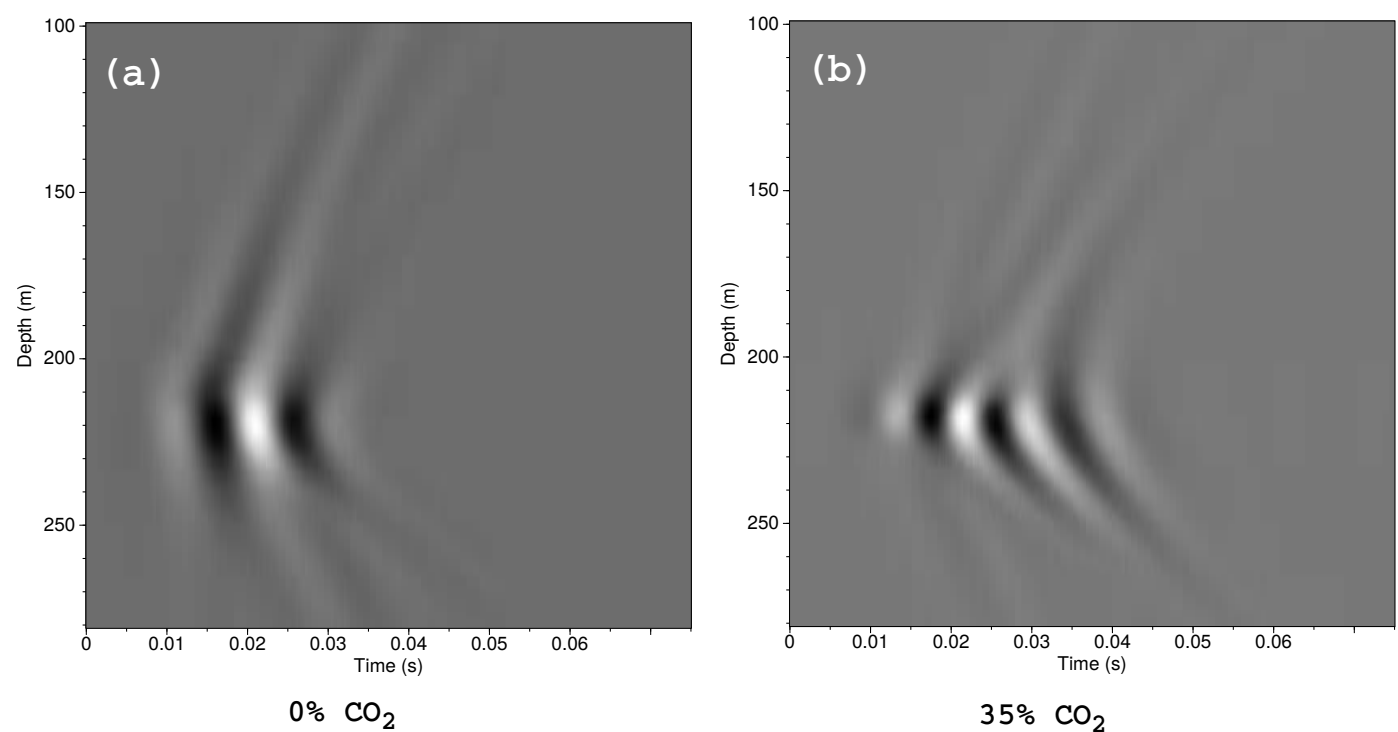

Figure 7. Well \#1 z-component acceleration gather, before $\mathrm{CO}_{2}$ pumping (a), and when $\mathrm{CO}_{2}$ saturation reaches $35 \%$. 
(a)

Solid $\times$ Acceleration $\left[\mathrm{m} / \mathrm{s}^{2}\right]$



(b)

Solid $z$ Acceleration $\left[\mathrm{m} / \mathrm{s}^{2}\right]$



Figure 8. Well \#1 acceleration traces, (a) x-component (b) z-component, before pumping $\mathrm{CO}_{2}$ into the reservoir and with $\mathrm{CO}_{2}$ saturations of $35 \%$ and $60 \%$, for a receiver located at $190 \mathrm{~m}$ depth, i.e., above the seal layer. 
(a)

Solid $x$ Acceleration $\left[\mathrm{m} / \mathrm{s}^{2}\right]$

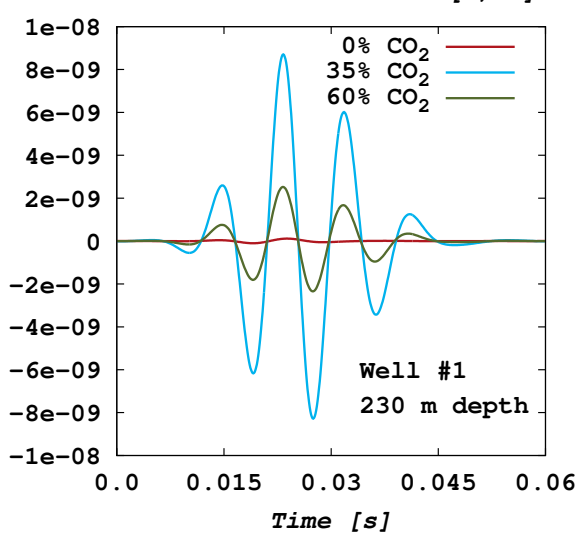

(b)

Solid $z$ Acceleration $\left[\mathrm{m} / \mathrm{s}^{2}\right]$

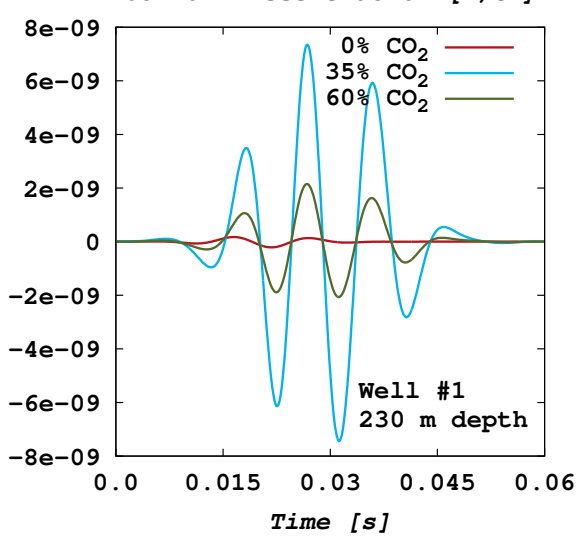

Figure 9. Well \#1 acceleration traces, (a) $\mathrm{x}$-component (b) z-component, before pumping $\mathrm{CO}_{2}$ into the reservoir and with $\mathrm{CO}_{2}$ saturations of $35 \%$ and $60 \%$, for a receiver located at $230 \mathrm{~m}$ depth, i.e., below the $\mathrm{CO}_{2}$ plume. 
(a)

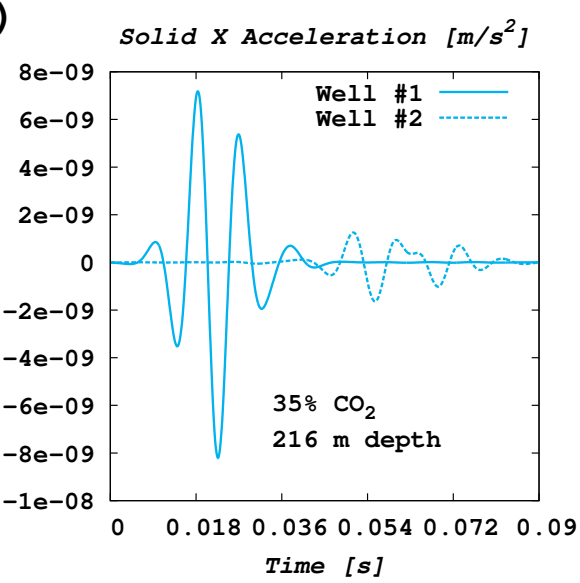

(b) Solid $z$ Acceleration $\left[\mathrm{m} / \mathrm{s}^{2}\right]$

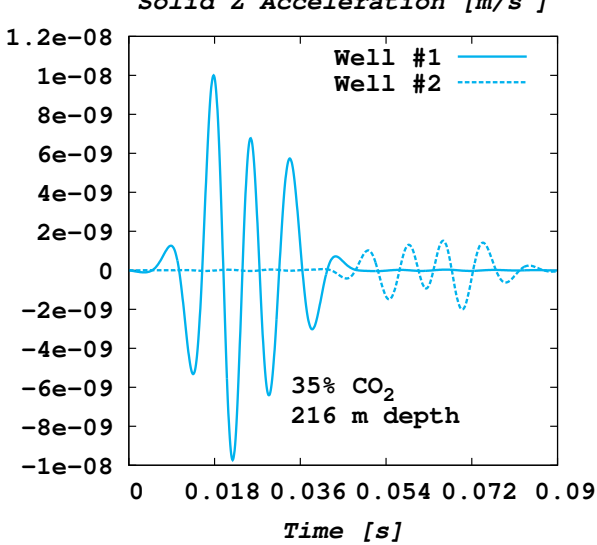

Figure 10. Comparison of Well \#1 and Well \#2 solid acceleration traces traces, for a receiver located at $216 \mathrm{~m}$ depth, i.e. at the same level as the $\mathrm{CO}_{2}$ plume, for (a) $\mathrm{x}$-component (b) z-component. $\mathrm{CO}_{2}$ saturation is $35 \%$. 
Surface Acceleration Traces, $\mathbf{z}$ component

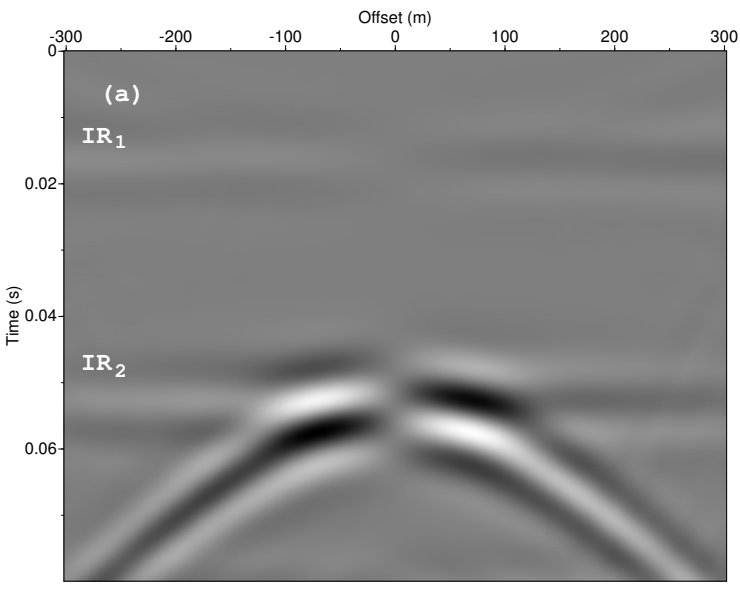

$0 \div \mathrm{CO}_{2}$

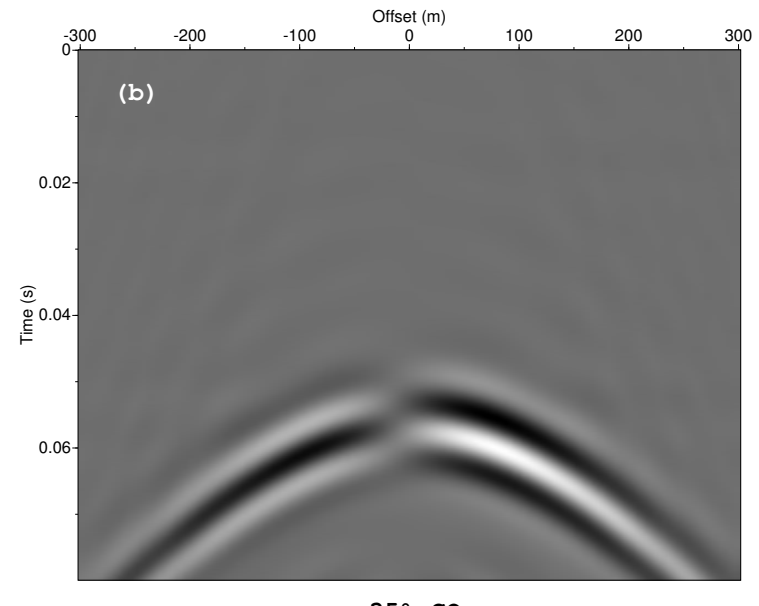

$35 \% \mathrm{CO}_{2}$

Figure 11. Surface acceleration traces, $\mathrm{z}$ component, (a) before pumping $\mathrm{CO}_{2}$ into the reservoir, (b) $35 \%$ $\mathrm{CO}_{2}$ saturation. 


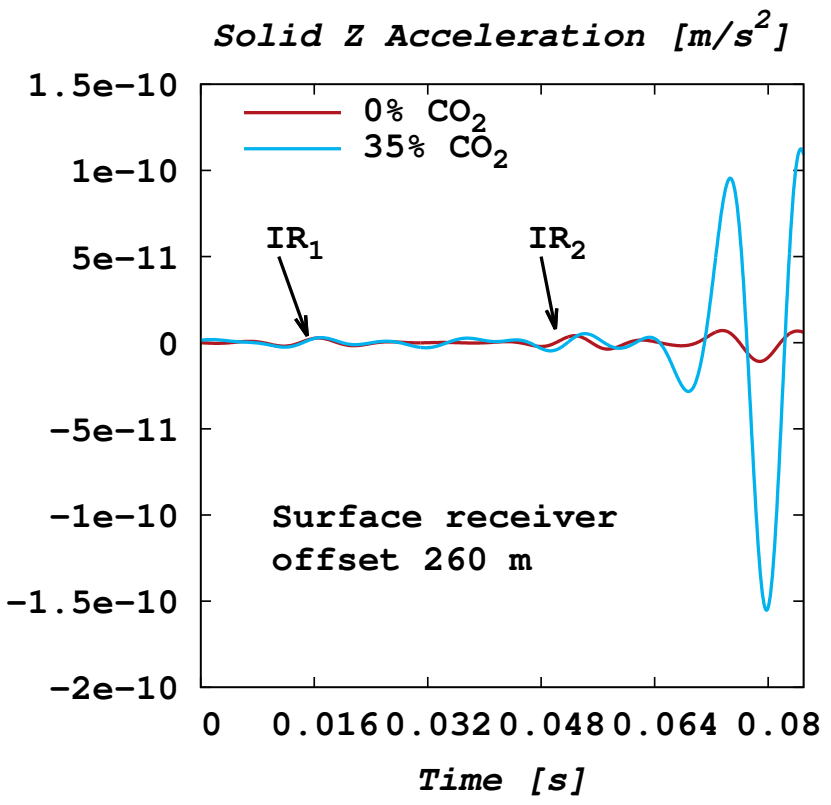

Figure 12. Surface acceleration traces, $\mathrm{z}$ component, taken at $260 \mathrm{~m}$ offset, before injection of $\mathrm{CO}_{2}$ and at $35 \% \mathrm{CO}_{2}$ saturation. 
(a)



(b)

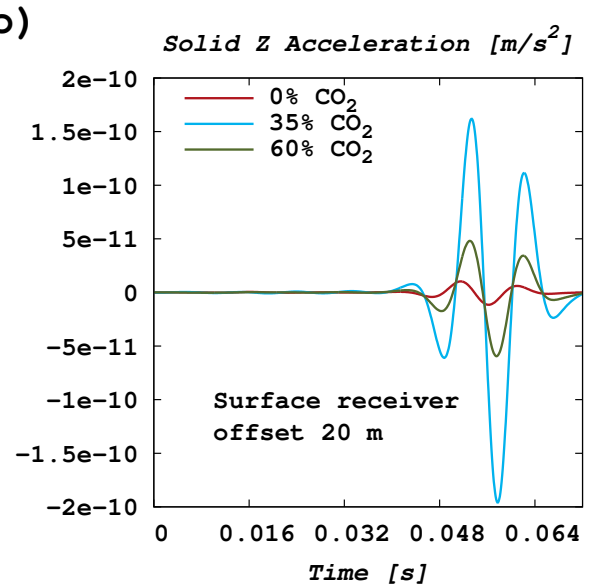

Figure 13. Surface acceleration traces, (a) $\mathrm{x}$-component (b) z-component, before pumping $\mathrm{CO}_{2}$ into the reservoir and with $\mathrm{CO}_{2}$ saturations of $35 \%$ and $60 \%$, for a receiver located at $20 \mathrm{~m}$ offset. 


\section{References}

Agrawal, P., V. Agrawal, M. Bushnell, and J. Sienicki (1994), Superlinear Speedup in Multiprocessing Environment, in First International Workshop on Parallel Processing.

Allègre, V., L. Jouniaux, F. Lehmann, and P. Sailhac (2010), Streaming Potential dependence on water-content in fontainebleau sand, Geophys. J. Int., 182, 1248-1266, doi:10.1111/j.1365-246X.2010.04716.x.

Allègre, V., L. Jouniaux, F. Lehmann, and P. Sailhac (2011), Reply to the comment by A. Revil and N. Linde on: "Streaming potential dependence on water-content in fontainebleau sand" by V. Allègre, L. Jouniaux, F. Lehmann and P. Sailhac, Geophys. J. Int., $186,115-117$.

Allègre, V., F. Lehmann, P. Ackerer, L. Jouniaux, and P. Sailhac (2012), Modelling the streaming potential dependence on water content during drainage: 1. A 1D modelling of SP using finite element method, Geophys. J. Int., 189, 285-295, doi:10.1111/j.1365246X.2012.05371.x.

Allègre, V., A. Maineult, F. Lehmann, F. Lopes, and M. Zamora (2014), Self-potential response to drainage-imbibition cycles, Geophys. J. Int., 197, 1410-1424, doi: $10.1093 / g j i / g g u 055$.

Allègre, V., L. Jouniaux, F. Lehmann, P. Sailhac, and R. Toussaint (2015), Influence of water pressure dynamics and fluid flow on the streaming-potential response for unsaturated conditions, Geophysical Prospecting, 63, 694-712, doi:10.1111/1365-2478.12206.

Alumbaugh, D. L., G. A. Prevost, and J. N. Shadid (1996), Three-dimensional wide band electromagnetic modeling on massively parallel computers, Radio Science, 31, 1-23.

Biot, M. A. (1956a), Theory of propagation of elastic waves in a fluid-saturated porous solid: I. low frequency range, J. Acoust. Soc. Am., 28(2), 168-178.

Biot, M. A. (1956b), Theory of propagation of elastic waves in a fluid-saturated porous solid: II. high frequency range, J. Acoust. Soc. Am., 28(2), 178-191.

Biot, M. A. (1956c), Theory of deformation of a porous viscoelastic anisotropic solid, $J$. Appl. Phys., 27, 459-467.

Biot, M. A. (1962), Mechanics of deformation and acoustic propagation in porous media, J. Appl. Phys., 34(1), 36-40.

Bordes, C., P. Sénéchal, J. Barrière, D. Brito, E. Normandin, and D. Jougnot (2015), Impact of water saturation on seismoelectric transfer functions:a laboratory study of 
coseismic phenomenon, Geophys. J. Int., 200, 1317-1335, doi:10.1093/gji/ggu464.

Borner, J., V. Herdegen, J. Repke, and K. Spitzer (2013), The impact of $\mathrm{CO}_{2}$ on the electrical properties of water bearing porous media-laboratory experiments with respect to carbon capture and storage, Geophysical Prospecting, 61, 446-460, doi:10.1111/j.13652478.2012.01129.x.

Brie, A., F. Pampuri, A. Marsala, and O. Meazza (1995), Shear sonic interpretation in Gas Bearing sands, Society of Petroleum Engineers.

Brovelli, A., G. Cassiani, E. Dalla, F. Bergamini, D. Pitea, and A. M. Binley (2005), Electrical properties of partially saturated sandstones: Novel computational approach with hydrogeophysical applications, Water Resources Research, 41, 12pp.

Butler, K., R. Russell, A. Kepic, and M. Maxwell (1996), Measurements of the seismoelectric response from a shallow boundary, Geophysics, 61, 1769-1778.

Cairns, G., H. Jakubowics, L. Lonergan, and A. Muggeridge (2012), Using time-lapse seismic monitoring to identify trapping mechanisms during $\mathrm{CO}_{2}$ sequestration, International Journal of Greenhouse Gas Control, 11, 316-325.

Carcione, J., and S. Picotti (2006), P-wave seismic attenuation by slow-wave diffusion: effects of inhomogeneous rock properties, Geophysics, 71(3), O1-08.

Carcione, J., G. Seriani, and D. Gei (2003), Acoustic and electromagnetic properties of soil saturated with salt water and NAPL, Journal of Applied Geophysics, 52, 177-191.

Carcione, J., S. Picotti, D. Gei, and G. Rossi (2006a), Physics and seismic modeling for monitoring $\mathrm{CO}_{2}$ storage, Pure and Applied Geophysics, 163(1), 175-207.

Carcione, J. M. (2001), Wave fields in real media: Wave propagation in anisotropic, anelastic and porous media, Handbook of Geophysical Exploration, vol. 31, Pergamon Press Inc., Amsterdam.

Carcione, J. M., S. Picotti, D. Gei, and G. Rossi (2006b), Physics and seismic modelling for monitoriong $\mathrm{CO}_{2}$ storage, Pure and applied geophysics, 163, 175-207.

Chotiros, N., and M. Isakson (2004), A broadband model of sandy ocean sediments: BiotStoll with contact squirt flow and shear drag, J. Acoust. Soc. Am., 116(4), 2011-2022.

Darwish, N., and N. Hilal (2010), A simple model for the prediction of $\mathrm{CO}_{2}$ solubility in $\mathrm{H}_{2}-\mathrm{NaCl}$ system at geological sequestration conditions, Desalinization, 260, 114-118, doi:10.1016/j.desal.2010.04.056.

Douglas, J., Jr., P. J. P. Leme, J. E. Roberts, and J. Wang (1993), A parallel iterative procedure applicable to the approximate solutio $\mathrm{n}$ of second order partial differential 
equations by mixed finite element methods, Numer. Math., 65, 95-108.

Douglas, Jr., J., J. E. Santos, D. Sheen, and Y. X (1999), Nonconforming Galerkin methods based on quadrilateral elements for second order elliptic problems, RAIRO Mathematical Modelling and Numerical Analysis (M2AN), 33, 747-770.

Dupuis, J. C., K. E. Butler, and A. W. Kepic (2007), Seismoelectric imaging of the vadose zone of a sand aquifer, Geophysics, 72, A81-A85, doi:10.1190/1.2773780.

Dvorkin, J., and A. Nur (1993), Dynamic poroelasticity: a unified model with the squirt and the biot mechanisms, Geophysics, 58, 524-533.

Dvorkin, J., G. Mavko, and A. Nur (1995), Squirt flow in fully saturated rocks, Geophysics, 60, 97-107.

Faber, V., O. Lubeck, and J. A. B. White (1986), Superlinear speedup of an efficient sequential algorithm is not possible, Parallel Comput., 3(3), 259-260.

Foster, J. (1995), Designing and building parallel programs, Addison Wesley, also available online, http://www.mcs.anl.gov/ itf/dbpp/.

Frenkel, J. (1944), On the theory of seismic and electroseismic phenomena in a moist soil, J. Phys., 8(4), 230-241.

Gander, M. J., F. Margoulès, and F. Nataf (2002), Optimized schwarz methods without overlap for the helmholtz equation, SIAM Journal on Scientific Computing, 24(1), 38-60.

Gander, M. J., C. Japhet, Y. Maday, and F. Nataf (2004), A new cement to glue nonconforming grids with Robin interface conditions: The finite element case, in Lecture Notes in Computational Science and Engineering, edited by R. Kornhuber, R. Hoppe, J. Periaux, O. Pironneau, O. Widlund, and J. Xu, Springer.

Garambois, S., P. Senechal, and H. Perroud (2002), On the use of combined geophysical methods to access water content and water conductivity of near surface formations, $J$. Hydrol., 259, 32-48.

Gassmann, F. (1951), Über die elastizität poröser medien (On the elasticity of porous media), Vierteljahrsschrift der Naturforschenden Gessellschaft in Zurich, 96, 1-23, cHE 1856-1999 246.

Gauzellino, P., F. Zyserman, and J. Santos (2009), Nonconforming finite element methods for the three dimensional Helmholtz equation: iterative domain decomposition or global solution?, Journal of Computational Acoustics, 17(2), 159-173.

Gauzellino, P., F. Zyserman, and J. Santos (2010a), Seismic and electromagnetic waves in the study of layers near-surface, Eos Trans. AGU, Meet. Am. Suppl., Abstract NS11B-21, 
91, 26.

Gauzellino, P., J. Santos, and F. Zyserman (2010b), Numerical simulation of seismoelectrograms, Mecnica Computacional, 29, 2309-2322.

Grobbe, N., and E. Slob (2013), Validation of an electroseismic and seismoelectric modeling code, for layered earth models, by the explicit homogeneous space solutions.

Grobbe, N., and E. Slob (2014), Seismoelectric interface response signal behaviour in thin-bed geological settings, in Expanded Abstracts, pp. 3428-3422, Soc. Expl. Geophys.

Grobbe, N., and E. C. Slob (2016), Seismo-electromagnetic thin-bed responses: Natural signal enhancements?, Journal of Geophysical Research: Solid Earth, 121(4), 24602479, doi:10.1002/2015JB012381.

Grobbe, N., J. Hunziker, and E. Slob (2014), Seismoelectric wave propagation modeling for typical laboratory configurations: A numerical validation, in Expanded Abstracts, pp. 2072-2077, Soc. Expl. Geophys.

Guan, W., and H. Hu (2008), Finite-difference modeling of the electroseismic logging in a fluid-saturated porous formation, Journal of Computational Physics, 227, 5633-5648.

Guichet, X., L. Jouniaux, and J.-P. Pozzi (2003), Streaming potential of a sand column in partial saturation conditions, J. Geophys. Res., 108(B3), 2141, doi: 10.1029/2001JB001517.

Haartsen, M., and S. Pride (1997), Electroseismic waves from point sources in layered media, Journal Geophysical Research, 102(24), 745-769.

Haines, S. H., and S. R. Pride (2006), Seismoelectric numerical modeling on a grid, Geophysics, 71(6), 57-65.

Haines, S. S., A. Guitton, and B. Biondi (2007a), Seismoelectric data processing for surface surveys of shallow targets, Geophysics, 72, G1-G8, doi:10.1190/1.2424542.

Haines, S. S., S. R. Pride, S. L. Klemperer, and B. Biondi (2007b), Seismoelectric imaging of shallow targets, Geophysics, 72, G9-G20, doi:10.1190/1.2428267.

Han, Q., and Z. Wang (2001), Time-domain simulation of SH-wave-induced electromagnetic field in heterogeneous porous media: A fast finite element algorithm, Geophysics, 66(2), 448-461, doi:10.1190/1.1444936.

Hornbostel, S., and A. Thompson (2007), Waveform design for electroseismic exploration, Geophysics, 72(2), Q1-Q10, doi:10.1190/1.2436473. 
Hu, H., and Y. Gao (2011), Electromagnetic field generated by a finite fault due to electrokinetic effect, J. Geophys. Res., 116, 1132-1143,.

Hu, H., and J. Liu (2002), Simulation of the converted electric field during acoustoelectric logging, 72nd SEG Annual International Meeting, Expanded Abstracts,21(Salt Lake City, Utah, USA), 348-351, doi:10.1029/2001JB001517.

Hu, H., W. Guan, and J. Harris (2007), Theoretical simulation of electroacoustic borehole logging in fluid-saturated porous formation, J. Acoust. Soc. Amer., 122, 135-145.

Ishido, T., J. Pritchett, T. Tosha, Y. Nishi, and S. Nakanishi (2013), Monitoring underground migration of sequestered $\mathrm{CO}_{2}$ using self-potential methods, Energy Procedia, 37, 4077-4084.

Jackson, M. D. (2010), Multiphase electrokinetic coupling: Insights into the impact of fluid and charge distribution at the pore scale from a bundle of capillary tubes model, $J$. Geophys. Res., 115, B07,206, doi:10.1029/2009JB007092,2010.

Japhet, C., and F. Nataf (2001), Artificial Boundary Conditions, chap. The best interface conditions for domain decomposition methods: Absorbing boundary conditions, Haupagne, NY.

Jardani, A., and A. Revil (2015), Seismoelectric couplings in a poroelastic material containing two immiscible fluid phases, Geophys. J. Int., 202, 850-870, doi: 10.1093/gji/ggv176.

Jougnot, D., N. Linde, E. Haarder, and M. Looms (2015), Monitoring of saline tracer movement with vertically distributed self-potential measurements at the HOBE agricultural site, Voulund, Denmark., Journal of Hydrology, 521, 314-327, doi: 10.1016/j.jhydrol.2014.11.041.

Jouniaux, L., and T. Ishido (2012), Electrokinetics in Earth Sciences: a tutorial, Int. J. Geophysics, vol. 2012(Hindawi Publishing Corporation), Article ID 286,107, doi: $10.1155 / 2012 / 286107$.

Jouniaux, L., and F. Zyserman (2016), A review on electrokinetically induced seismoelectrics, electro-seismics, and seismo-magnetics for Earth sciences, Solid Earth, 7, 249-284, doi:10.5194/se-7-249-2016.

Kazemeini, S., C. Juhlin, and S. Fomel (2010), Monitoring $\mathrm{CO}_{2}$ response on surface seismic data; a rock physics and seismic modeling feasibility study at the $\mathrm{CO}_{2}$ sequestration site, Ketzin, Germany, Journal of Applied Geophysics, 71, 109-124, doi: 10.1016/j.jappgeo.2010.05.004. 
Kiessling, D., C. Schmidt-Hattemberger, H. Schuett, F. Schilling, K. Krueger, B. Schoebel, E. Dankwardt, and J. Kummerow (2010), Geoelectrical methods for monitoring geological $\mathrm{CO}_{2}$ storage: First results from cross-hole and surface-downhole measurements from the $\mathrm{CO}_{2}$ SINK test site at Ketzin (Germany), International Journal of Greenhouse Gas Control, 4, 816-826, doi:10.1016/j.ijggc.2010.05.001.

Kim, J., M. Nam, and T. Matsuoka (2013), Estimation of $\mathrm{CO}_{2}$ saturation during both $\mathrm{CO}_{2}$ drainage and imbibition processes based on both seismic velocity and electrical resistivity measurements, Geophys. J. Int., electronical access July 9th, doi:10.1093/gji/ggt232.

Kim, S. (1995), Domain decomposition methods for contamintant transport in fractured porous media, Ph.D. thesis, Purdue University.

Kröger, B., U. Yaramanci, and A. Kemna (2014), Numerical analysis of seismoelectric wave propagation in spatially confined geological units, Geophysical Prospecting, 62, 133-147, doi:10.1111/1365-2478.12020

Liu, H.-P., L. Don, and H. Kanamori (1976), Velocity dispersion due to anelasticity; implications for seismology and mantle composition, J. Geophys. Res., 147, 41-58.

Mavko, G., and D. Jizba (1991), Estimating grain-scale fluid effects on velocity dispersion in rocks, Geophysics, 56, 1940-1949.

Mavko, G., T. Mukerji, and J. Dvorkin (2009), The rock physics handbook: Tools for seismic analysis of porous media, Cambridge University Press, The Pitt Building, Trumpington Street, Cambridge CB2 IRP, United Kingdom.

Mboh, C. M., J. A. Huisman, E. Zimmermann, and H. Vereecken (2012), Coupled hydrogeophysical inversion of streaming potential signals for unsaturated soil hydraulic properties, Vadose Zone J., 11(2), doi:10.2136/vzj2011.0115.

Mikhailov, O. V., M. W. Haartsen, and M. N. Toksöz (1997), Electroseismic investigation of the shallow subsurface: Field measurements and numerical modeling, Geophysics, $62,97-105$.

Moore, J., S. Glaser, and H. Morrison (2004), The streaming potential of liquid carbon dioxide in berea sandstone, Geophys. Res. Lett., 31, L17,610, doi: 10.1029/2004GL020774.

Munch, F., and F. Zyserman (2016), Detection of Non-Aqueous Phase Liquids Contamination by SH-TE Seismoelectrics: a Computational Feasibility Study, Journal of Applied Geophysics, doi:10.1016/j.jappgeo.2016.03.026.

Nedelec, J. C. (1980), Mixed finite elements in $\mathbb{R}^{3}$, Numer. Math., 35, 315-341. 
Newman, G., and D. Alumbaugh (1997), Three-dimensional massively parallel electromagnetic inversion-i. theory, Geophys. J. Int., 128, 345-354.

Pacheco, P. (2011), An introduction to parallel programming, Morgan Kaufmann.

Pain, C., J. H. Saunders, M. H. Worthington, J. M. Singer, C. W. Stuart-Bruges, G. Mason, and A. Goddard. (2005), A mixed finite-element method for solving the poroelastic Biot equations with electrokinetic coupling, Geophys. J. Int., 160, 592-608.

Perrier, F., and P. Morat (2000), Characterization of electrical daily variations induced by capillary flow in the non-saturated zone, Pure Appl. Geophys., 157, 785-810.

Picotti, S., J. Carcione, J. Rubino, and J. Santos (2007), P-wave seismic attenuation by slow-wave diffusion: Numerical experiments in partially saturated rocks, Geophysics, 72(4), N11-N21.

Pride, S. (1994), Governing equations for the coupled electromagnetics and acoustics of porous media, Phys. Rev. B: Condens. Matter, 50, 15,678-15,695.

Pride, S., and S. Garambois (2005), Electroseismic wave theory of Frenkel and more recent developments, Journal of Engineering Mechanics, 131(9), 697-706.

Pride, S., and F. D. Morgan (1991), Electrokinetic dissipation induced by seismic waves, Geophysics, 56(7), 914-925.

Pride, S. R., J. G. Berryman, and J. M. Harris (2004), Seismic attenuation due to waveinduced flow, J. Geophys. Res., 109, 10.1029/2003JB002,639.

Raviart, P. A., and J. M. Thomas (1975), Mixed finite element method for $2^{\text {nd }}$ order elliptic problems, Mathematical Aspects of the Finite Element Methods, Lecture Notes of Mathematics, vol. 606, Springer.

Reuss, F. (1809), Sur un nouvel effet de l'éléctricité galvanique, Mémoires de la société impériale des naturalistes de Moscou, 2, 326-337.

Revil, A., N. Linde, A. Cerepi, D. Jougnot, S. Matthäi, and S. Finsterle (2007), Electrokinetic coupling in unsaturated porous media, J. Colloid Interface Sci., 313, 315-327.

Rubino, J. G., C. L. Ravazzoli, and J. E. Santos (2008), Biot-type scattering effects in gas hydrate-bearing sediments, J. Geophys. Res., 113, B06,102.

Santos, J., C. Ravazzoli, P. Gauzellino, J. Carcione, and F. Cavallini (2004a), Simulation of waves in poro-viscoelastic rocks saturated by immiscible fluids. numerical evidence of a second slow wave., J. Comput. Acoust., 12, 1-21.

Santos, J. E. (1998), Global and domain-decomposed mixed methods for the solution of Maxwell's equation with application to magnetotellurics, Numerical Methods for Partial 
Differential Equations, 14, 263-280.

Santos, J. E. (2009), Finite element approximation of coupled seismic and electromagnetic waves in fluid-saturated poroviscoelastic media, NMPDE, p. doi:10.1002/num.20527.

Santos, J. E., and D. Sheen (2007), Finite element methods for the simulation of waves in composite saturated poroviscoelastic media, SIAM Journal of Numerical Analysis, 45(1), 389-420.

Santos, J. E., J. Douglas, Jr., M. E. Morley, and O. M. Lovera (1992), Reflection and transmission coefficients in fluid-saturated porous media, J. Acoust. Soc. Amer, 91, 1911-1923.

Santos, J. E., C. L. Ravazzoli, and J. M. Carcione (2004b), A model for wave propagation in a composite solid matrix saturated by a single-phase fluid, J. Acoust. Soc. Amer., 115(6), 2749-2760.

Santos, J. E., C. L. Ravazzoli, P. M. Gauzellino, and J. M. Carcione (2005), Numerical simulation of ultrasonic waves in reservoir rocks with patchy saturation and fractal petrophysicas properties, Computational Geosciences, 9, 1-27.

Saunders, J. H., M. D. Jackson, and C. C. Pain (2008), Fluid flow monitoring in oilfields using downhole measurements of electrokinetic potential, Geophysics, 73, E165-E180, doi:10.1190/1.2959139.

Savioli, G., J. Santos, J. Carcione, and D. Gei (2014), Numerical modelling of fluid flow and time lapse seismograms applied to $\mathrm{CO}_{2}$ storage and monitoring.

Shan, J. (2002), Superlinear Speedup in parallel computation, Tech. rep., Northeastern University, Massachusetts.

Sheen, D. (1997), Approximation of electromagnetic fields: Part I. Continuous problems, SIAM J. Appl. Math., 57(6), 1716-1736.

Smoluchowski, M. (1903), Ph.D. thesis, M. Krak. Anz, 182.

Song, Y., H. Hu, and L. Rudnicki (2016), Dynamic bulk and shear moduli due to grainscale local fluid flow in fluid-saturated cracked poroelastic rocks: Theoretical model, Journal of the Mechanics and Physics of Solids, 92, 2854.

Strahser, M., L. Jouniaux, P. Sailhac, P.-D. Matthey, and M. Zillmer (2011), Dependence of seismoelectric amplitudes on water-content, Geophys. J. Int., 187, 1378-1392.

Teja, A. S., and P. Rice (1981), Generalized corresponding states method for the viscosities of liquid mixtures, Ind. Eng. Chem. Fund., 20(1), 77-81. 
Thompson, A., S. Hornbostel, J. Burns, T. Murray, R. Raschke, J. Wride, P. McCammon, J. Sumner, G. Haake, M. Bixby, W. Ross, B. White, M. Zhou, and P. Peczak (2005), Field tests of electroseismic hydrocarbon detection, SEG Technical Program Expanded Abstracts, pp. 565-568.

Thompson, A., J. Sumner, and S. Hornbostel (2007), Electromagnetic-to-seismic conversion: A new direct hydrocarbon indicator, The Leading Edge, 26, 428-435, doi: $10.1190 / 1.2723205$

Thompson, A. H., and G. A. Gist (1993), Geophysical applications of electrokinetic conversion, The Leading Edge, 12, 1169-1173.

Thompson, R. R. (1939), A note on the seismic-electric effect, Geophysics, 4(2), 102-103.

Thyssen, S. V., J. Hummel, and O. Rülke (1937), Die ursachen des seismisch-elektrischen effektes, Z. Geophs., 13, 112-119.

Toselli, A., and O. Widlund (2005), Domain Decomposition Methods - Algorithms and Theory., Springer.

von Helmholtz, H. (1879), Studien uber elektrische grenzschichten, Annalen der Physik und Chemie, Neue Folge, 7(7), 337-382.

Wang, Z., H. Hu, and W. Guan (2013a), Three-dimensional finite-difference time-domain computation of the seismoelectric field generated by a slipping fault, in Poromechanics V: Proceedings of the Fifth Biot Conference on Poromechanics, vol. Vienna, Australia, edited by C. Hellmich, B. Pichler, and D. Adam, pp. 2032-2041.

Wang, Z., M. Small, and A. Karamalidis (2013b), Multimodel predictive system for carbon dioxide solubility in saline formation waters, Environmental Science and Technology, 47, 1407-1415, doi:10.1021/es303842j.

Warden, S., S. Garambois, L. Jouniaux, D. Brito, P. Sailhac, and C. Bordes (2013), Seismoelectric wave propagation numerical modeling in partially saturated materials, Geophys. J. Int., 194, 1498-1513, doi:10.1093/gji/ggt198.

Wiedemann, G. (1852), Uber die bewegung von Flussigkeiten im Kreise der geschlossenen galvanischen saule., Annalen der Physik und Chemie, 87(11), 321-352.

Zheng, X., H. Hu, W. Guan, and J. Wang (2015), Simulation of the borehole quasistatic electric field excited by the acoustic wave during logging while drilling due to electrokinetic effect, Geophysics, 80(5), D417-D427.

Zhou, J., Z. Cui, and W. Lü (2014), Seismoelectric waves in a borehole excited by an external explosive source, Chin. Phys. B, 23(1), 014,301-1-014,301-6. 
Zyserman, F., P. Gauzellino, and J. Santos (2010), Finite element modeling of SHTE and PSVTM electroseismics, J. Applied Geophysics, 72, 79-91, doi: 10.1016/j.jappgeo.2010.07.004.

Zyserman, F., P. Gauzellino, and J. Santos (2012), Numerical evidence of gas hydrate detection by means of electroseismics, J. Applied Geophysics, 86, 98-108.

Zyserman, F., L. Jouniaux, S. Warden, and S. Garambois (2015), Borehole seismoelectric logging using a shear-wave source:Possible application to $\mathrm{CO}_{2}$ disposal?, International Journal of Greenhouse Gas Control, 33, 82-102, doi:10.1016/j.ijggc.2014.12.009.

Zyserman, F. I., and J. E. Santos (2000), Parallel finite element algorithm for threedimensional magnetotelluric modelling, Journal of Applied Geophysics, 44, 337-351.

Zyserman, F. I., L. Guarracino, and J. E. Santos (1999), A hybridized mixed finite element domain decomposed method for two-dimensional magnetotelluric modelling, Earth, Planets and Space, 51, 297-306. 